\title{
Global structure, seasonal and interannual variability of the migrating semidiurnal tide seen in the SABER/TIMED temperatures (2002-2007)
}

\author{
D. Pancheva, P. Mukhtarov, and B. Andonov \\ Geophysical Institute, Bulgarian Academy of Sciences, Sofia, Bulgaria
}

Received: 14 October 2008 - Revised: 4 January 2009 - Accepted: 16 January 2009 - Published: 12 February 2009

\begin{abstract}
The present paper is focused on the global spatial (altitude and latitude) structure, seasonal and interannual variability of the migrating semidiurnal tide derived from the SABER/TIMED temperature measurements for 6 years (January 2002-December 2007). The tidal results are obtained by a new analysis method where the tides (migrating and nonmigrating) and the planetary waves (zonally travelling and stationary) are simultaneously extracted from the satellite data. The strongest migrating semidiurnal tide has been derived at tropical latitudes $\left( \pm 20-30^{\circ}\right)$ where it revealed significant amplification between May and August in the lower thermosphere of both hemispheres. On the average, the semidiurnal temperature tide is stronger in the $\mathrm{SH}$ $(32 \mathrm{~K})$ than that in the $\mathrm{NH}(30 \mathrm{~K})$ and the tidal amplitudes at $110 \mathrm{~km}$ height are nearly a factor of 5 larger than those at $90 \mathrm{~km}$. The migrating semidiurnal tide in both hemispheres revealed remarkable seasonal behavior at the altitude where it maximizes, $\sim 110 \mathrm{~km}$ in the $\mathrm{NH}$ and $\sim 115 \mathrm{~km}$ in the $\mathrm{SH}$, indicating repeatable each year maxima exactly in May-June and August. However, while the main maximum in the NH is that in August, in the SH it is that in May. The vertical wavelengths indicated seasonal variability being larger in summer $(\sim 38-50 \mathrm{~km})$ than in winter $(\sim 25-35 \mathrm{~km})$. The seasonal behavior of the semidiurnal tide in the middle latitudes $\left( \pm 40^{\circ}\right)$ is dominated by annual variability with a winter maximum in the upper mesosphere $(90 \mathrm{~km})$ of both hemispheres and summer one in the lower thermosphere $(110 \mathrm{~km})$. The NH summer maximum (June and August peaks) is much stronger than that in the SH (November and March peaks) having amplitudes of $\sim 23 \mathrm{~K}$ and $\sim 13-15 \mathrm{~K}$ respectively. The vertical wavelengths at both hemispheres indicated slight seasonal changes and a mean vertical wavelength of $\sim 35 \mathrm{~km}$ is observed during most of the year. The interannual variability of
\end{abstract}

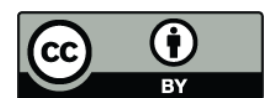

Correspondence to: D. Pancheva (dpancheva@geophys.bas.bg) the semidiurnal tide in the midlatitude lower thermosphere is at least partly connected with the stratospheric QBO as this effect is stronger in the $\mathrm{NH}$.

Keywords. Meteorology and atmospheric dynamics (Middle atmosphere dynamics; Thermospheric dynamics; Waves and tides)

\section{Introduction}

Atmospheric solar tides profoundly affect the large-scale dynamics of the mesosphere and lower thermosphere (MLT) where they attain large amplitudes and dominate the largescale wind and temperature fields. Like other waves the tidal components grow in amplitude with increasing altitude since atmospheric density decreases and energy must be conserved. Migrating (or Sun-synchronous) solar tides are global-scale atmospheric waves which propagate westward with the apparent motion of the Sun and have periods that are harmonics of a solar day. Thus the migrating semidiurnal tide is a westward propagating zonal wavenumber 2 (W2) perturbation. The migrating tides are forced predominantly in the troposphere and stratosphere and propagate vertically to the lower thermosphere. The absorption of solar radiation by a zonally uniform medium gives rise to migrating solar tides. Their presence in the atmosphere is due to the tropospheric water vapor $\left(\mathrm{H}_{2} \mathrm{O}\right)$ absorption of infrared radiation (IR), stratospheric and lower mesospheric ozone $\left(\mathrm{O}_{3}\right)$ absorption of ultraviolet (UV) radiation, mesospheric molecular oxygen $\left(\mathrm{O}_{2}\right)$ absorption in the Schumann-Runge bands and continuum, and thermospheric oxygen absorption of extreme ultraviolet (EUV) radiation (Chapman and Lindzen, 1970; Forbes and Garret, 1979; Groves, 1982a, b). The release of latent heat by deep convective clouds is another possible source that could generate nonnegligible tidal migrating and nonmigrating response in the MLT (Hamilton,

Published by Copernicus Publications on behalf of the European Geosciences Union. 
1981; Williams and Avery, 1996; Hagan, 1996; Forbes et al., 1997; Hagan and Forbes, 2003). Another important source of nonmigrating tides is the nonlinear interaction between the migrating tides and the stationary planetary waves (SPWs) (Angelats i Coll and Forbes, 2002).

Both ground-based and satellite observations have revealed many important features of the semidiurnal tide. A major advantage of the ground-based methods is their ability to study in detail seasonal, intraseasonal and interannual variability of the tides in the MLT at various geographic points (Bernard, 1981; Avery et al., 1989; Manson et al., 1990, 1999; Clark and Salah, 1991; Vincent et al., 1998; Jacobi et al., 1999; Pancheva et al., 2000, 2002), as well as their vertical structure including vertical wavelengths and direction of propagation (Mitchell et al., 2002; She et al., 2004; Yuan et al., 2008). A disadvantage of the ground-based methods is their inability to distinguish between global and local signatures and to provide only coarse information on spatial (latitudinal and longitudinal) structures of the tides. The seasonal variation of the MLT semidiurnal tide observed by MF radars showed an autumn equinox maximum localized at height $\sim 85-88 \mathrm{~km}$ (Manson et al., 2002; Riggin et al., 2003), while the meteor radar measurements not only documented this localized autumn maximum, but indicated also an amplification of the tide again above $\sim 93-95 \mathrm{~km}$ altitude (Manson et al., 2004). The meteor radar observations revealed also that the winter maximum of the semidiurnal tide is actually the main maximum in the MLT region (Mitchell et al., 2002; Manson et al., 2004; Pancheva and Mitchell, 2004). The winter maximum of the semidiurnal tide was documented by the lidar (Yuan et al., 2008) and satellite (Burrage et al., 1995) measurements as well. Observational studies of the semidiurnal tide have revealed a very high degree of variability in tidal characteristics occurring over a range of time scales including short-term (several days), seasonal and long-term (including interannual and solar-cycle) changes. Long-term variations of the semidiurnal tide are thought to arise from changes in the strength and distribution of the tidal forcing, and changes in the propagation characteristics of the tide as it ascends through the middle atmosphere from its predominantly troposphere/stratosphere sources towards the MLT region (Vial, 1989).

The satellite observations from the HRDI (High Resolution Doppler Imager), WINDII (Wind Imaging Interferometer) and MLS (Microwave Limb Sounder) instruments on board the UARS (Upper Atmosphere Research Satellite) satellite have provided a global scale picture of the semidiurnal tide seen in the neutral wind and temperature fields of the mesosphere and lower thermosphere (Burrage et al., 1995; McLandress et al., 1994, 1996; Forbes and Wu, 2006). It is important to note that the satellite observations enable the researchers to separate the nonmigrating from migrating semidiurnal tides and to study their global structures. Both ground-based and satellite observations have revealed that the migrating semidiurnal tide in the MLT region indicates a main maximum in the winter months when its amplitude increases with increasing the height and a secondary maximum in September when the maximum is localized near height of $85-88 \mathrm{~km}$.

Modelling studies have also made some progress in reproducing both the observed latitude-height structure in a particular season and the observed seasonal variability (Forbes, 1982; Vial, 1986; Portnyagin and Kajdalov, 1986; Forbes and Vial, 1989, Hagan et al., 1995, 1999, 2001; Hagan and Forbes, 2003). By combining observations from 23 groundbased radars from various locations Pancheva et al. (2002) were able to assemble the global pictures of the diurnal and semidiurnal tides and compared them with the GSWM-00 in order to investigate the model ability to simulate the solar tides in the mesopause region $(90-95 \mathrm{~km})$. It was found that the GSWM-00 provides a reasonable estimate of the tidal characteristics, however, the representation of the 24-h tide appears superior to that of the 12-h tide.

The measurements from the Sounding of the Atmosphere using Broadband Emission Radiometry (SABER) instrument (Russell et al., 1999) on the Thermosphere-IonosphereMesosphere-Energetics and Dynamics (TIMED) satellite have provided recently global kinetic temperature data from the lower stratosphere to the lower thermosphere. Since its launch on 7 December 2001, the TIMED satellite has been in orbit over 6 years. These measurements are very suitable for studying the long-term variability and the global spatial structure of the migrating and nonmigrating tides from approximately $20 \mathrm{~km}$ to $120 \mathrm{~km}$ altitude. Therefore, the focus is on the semidiurnal tidal coupling between multiple atmospheric regimes that include stratosphere, mesosphere and lower thermosphere. The present paper is going to report the climatological features of the migrating semidiurnal temperature tide produced for latitudes between $50^{\circ} \mathrm{N}$ and $50^{\circ} \mathrm{S}$ for the period of time between January 2002 and December 2007. Recently a complementary study of the migrating diurnal temperature tide based on the same SABER measurements has been presented by Mukhtarov et al. (2009). It is worth mentioning that some main features of the migrating diurnal and semidiurnal temperature tides have been already reported by Zhang et al. (2006) and Forbes et al. (2008). However, in the first mentioned paper the results are based on much shorter than 6-year period of time used in the present study; only a year (from September 2003 to September 2004) period of time has been investigated by Zhang et al. (2006). In Forbes et al. (2008) the migrating and nonmigrating diurnal and semidiurnal tides seen in the SABER/TIMED temperatures have been investigated for longer period of time, between 2002 and 2006, but only for altitudes between 100 and $116 \mathrm{~km}$. An important peculiarity of the present study is that the tidal results are derived by a new analysis method, described in detail by Pancheva et al. (2009a), where the tides (migrating and nonmigrating) and the planetary waves (zonally travelling, zonally symmetric and stationary) are simultaneously extracted from the satellite data. 


\section{Observations and method for data analysis}

\subsection{SABER temperature data}

The TIMED satellite was launched on 7 December 2001 and the SABER instrument began making observations in January 2002. It measures $\mathrm{CO}_{2}$ infrared limb radiance from approximately $20 \mathrm{~km}$ to $120 \mathrm{~km}$ altitude and the kinetic temperature profiles are retrieved over these heights using a full nonLTE inversion (Mertens et al., 2001, 2004). The retrieval errors, in addition to those associated with instrumental noise, are estimated by Mertens et al. (2001) and they have been found in the range between $1.4 \%$ at $80 \mathrm{~km}$ and $22.5 \%$ at $110 \mathrm{~km}$. In this study, however, the fidelity with which the temperature variations can be determined is primarily important. In this connection, apparent variations introduced into the SABER temperatures by unmodeled variability in the assumed atomic oxygen densities is of prime concern and for this reason the results at the upper altitude of $110-120 \mathrm{~km}$ should be accepted with caution (Forbes et al., 2006).

The SABER views the atmosphere $90^{\circ}$ to the satellite velocity vector in a $625 \mathrm{~km}$ and $73^{\circ}$ inclination orbit so that latitude coverage on a given day extends from about $53^{\circ}$ in one hemisphere to $83^{\circ}$ in the other. About every 60 days, the latitude ranges flip as the spacecraft yaws to keep the instrument on the anti-sun side of the spacecraft. In this way high latitude data are available only in 60-day segments, with no information for the 60 days preceding or following. This is the reason not to generate results poleward of $50^{\circ}$. The TIMED orbit precesses to cover $12 \mathrm{~h}$ of local time in each 60day yaw period, as ascending and descending data together give almost $24 \mathrm{~h}$ of local time sampling. Our results are derived from the version 1.07 of the SABER data, which were downloaded from the web site: http://saber.gats-inc.com/. It is worth noting that the latest version 1.07 is substantially improved particularly for the results in the upper mesosphere and lower thermosphere region (Garcia-Comas et al., 2008). The algorithms for both day and night data use monthly and diurnally averaged $\mathrm{CO}_{2}$ profiles from the distributions with latitude derived by the Whole Atmosphere Community Climate Model (WACCM) (Garcia et al., 2007). We use temperature data from January 2002 to December 2007, almost full 6 years, in order to study the temporal variability and global spatial structure of the migrating semidiurnal tide exhibited by the monthly mean tidal amplitudes and phases. The data were averaged into $5 \mathrm{~km}$ altitude and $10^{\circ}$ latitude bins and each bin was independently fit. We work in UT and for each altitude (from 20 to $120 \mathrm{~km}$ at each $5 \mathrm{~km}$ ) and latitude (from $50^{\circ} \mathrm{S}$ to $50^{\circ} \mathrm{N}$ at each $10^{\circ}$ ) the data were arranged in a matrix with 24 columns (this is the longitude with a step of $15^{\circ}$ ) and the number of rows is equal to the length of the considered period of time (January 2002-December 2007) in hours.

\subsection{Method for extracting waves from the Saber tem- peratures}

The data analysis method for calculating the monthly mean tidal characteristics has been described in detail in the complimentary paper of a migrating diurnal tide (Mukhtarov et al., 2009), therefore here it will be only briefly summarized. This method is composed by two steps: first, the daily characteristics of the investigated waves calculated for the entire 6-year period of time (2002-2007) are derived, and second, the monthly mean wave characteristics are calculated by geometrical averaging of the daily wave parameters for each calendar month. The seasonal behavior of the wave characteristics during the entire 6-year period of time is estimated by the geometrical averaging of the monthly mean wave characteristics for each month of the year.

In order to extract the waves from the SABER data (i.e. to determine their amplitudes and phases) at a given latitude and altitude, a linear two-dimensional (time-longitude) least-squares fitting is applied to a 60-day time segment of data (because it takes SABER 60 days to sample $24 \mathrm{~h}$ in local time by combining ascending and descending data together). Then this segment is moved through the time series with steps of 1 day in order to derive daily values of the wave amplitudes and phases. The decomposition includes: (i) diurnal and semidiurnal tides with zonal wavenumbers up to 4, (ii) zonally travelling planetary waves with zonal wavenumbers up to 3 (including zonally symmetric waves as well), and (iii) the first three modes of the SPWs, i.e. SPWs with zonal wavenumbers 1,2 and 3 . The well-known zonally travelling normal planetary wave modes with periods near 5,10 and 16 days are included in the fitting procedure. The $~ 24$-day wave is also regularly observed in the stratosphere and mesosphere particularly in the winter (Pancheva and Mitchell, 2004; Pancheva et al., 2008, 2009b), hence this planetary wave period is included in the fitting procedure as well. It is worth noting that the quasi-2-day wave is excluded from the fitting procedure because of its burst-like behavior with time scales near or less than a month and because of using a rather long time window, a 60-day one, for extracting the waves. All waves are extracted simultaneously in order to avoid a possible distortion of the weaker waves by the stronger ones and some aliasing between the tides and the SPWs. Over 60 days the temperature variations can be due to seasonal or intraseasonal time scales. A possible effect of the semiannual oscillation is expressed by including also a linear term in the temperature decomposition.

Because of the satellite data sampling pattern and the variability of the planetary waves during the 60-day time windows used for extracting the waves a very important problem in the tidal assessment is how to determine the reference noise level. We investigated in detail the winter stratosphere levels where the strong SPWs could affect the tidal results. For each 60-day time window we generated 100 Gaussian noise datasets with length of 60 days and with data sampling 


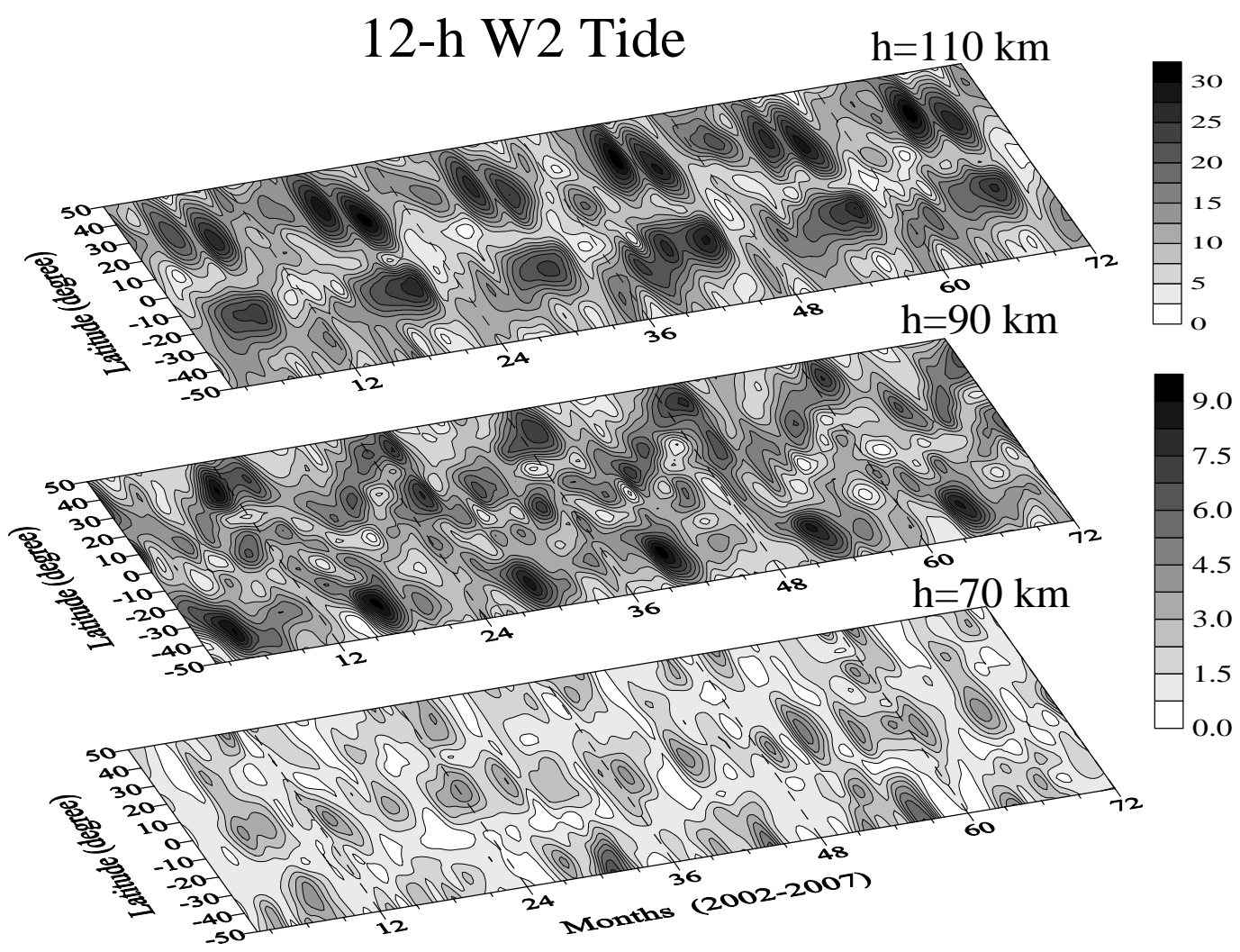

Fig. 1. Latitude-time cross sections of the semidiurnal tidal amplitudes (in Kelvin) at three altitudes: $110 \mathrm{~km}$ (upper plot), $90 \mathrm{~km}$ (middle plot) and $70 \mathrm{~km}$ (bottom plot); the scale (in Kelvin) for the $110 \mathrm{~km}$ level is different from that for $70 \mathrm{~km}$ and $90 \mathrm{~km}$.

pattern and variance as those of the true SABER measurements (Kong et al., 1998). Then the 2-D Lomb-Scargle periodogram has been performed on the resulting noise datasets. The reference noise spectrum for each zonal wavenumber is calculated as an average spectrum. The results from this analysis indicated that only because of data sampling pattern and the planetary wave variability in the winter time all noise spectra revealed a cluster of peaks near $24 \mathrm{~h}$ with amplitudes on the average between 0.55 and $0.95 \mathrm{~K}$. Therefore, all tidal waves extracted from a given 60-day time window with amplitudes larger than $1 \mathrm{~K}$ are accepted as statistically significant.

\section{Results}

The climatological features of the migrating semidiurnal temperatures are investigated by the distribution of the monthly mean tidal amplitudes and phases in the time and space (latitude and altitude). The result of data analysis covers with monthly mean tidal amplitudes and phases the interval between February 2002 and December 2007. Figure 1 shows the latitude $\left(50^{\circ} \mathrm{N}-50^{\circ} \mathrm{S}\right)$ - time cross sections of the tidal amplitudes for three altitudes: 70,90 and $110 \mathrm{~km}$. We note that below $70 \mathrm{~km}$ height the migrating 12-h tide is usually very weak. The scale (in Kelvin) of the plot for $110 \mathrm{~km}$ height is different from that used for 70 and $90 \mathrm{~km}$ indicating a very rapid growth of the tidal amplitude with increasing the height in the lower thermosphere. The results from Fig. 1 can be summarized as follows: (i) at $70 \mathrm{~km}$ level the semidiurnal tide maximizes mainly at the equator reaching amplitude of 4-4.5 K ; there is also some amplification near middle latitudes as the equatorial and midlatitude maxima are separated by almost absent of the semidiurnal tide at $\pm 20^{\circ}$; (ii) at $90 \mathrm{~km}$ altitude the semidiurnal tide maximizes toward middle latitudes, $\pm\left(30-40^{\circ}\right)$, reaching amplitude of $9 \mathrm{~K}$; the temporal variability is dominated by annual oscillation with a winter maximum; and (iii) in the lower thermosphere $(110 \mathrm{~km})$ the semidiurnal tide maximizes near tropics, $\pm\left(20-30^{\circ}\right)$, and in both hemispheres it reaches very large amplitude, $\sim 30 \mathrm{~K}$, between May and September; in the Northern Hemisphere (NH) there is a bifurcation of this maximum into two maxima respectively in May-June centered at $\sim 30^{\circ} \mathrm{N}$ and in AugustSeptember centered at $\sim 20^{\circ} \mathrm{N}$.

The results of Fig. 1 revealed some peculiarities of the semidiurnal tidal features over the equator (lower mesosphere), at middle latitudes (upper mesosphere) and at tropics (lower thermosphere). This is a reason the altitude structure of the migrating semidiurnal tide to be studied in detail at these latitude regions. 

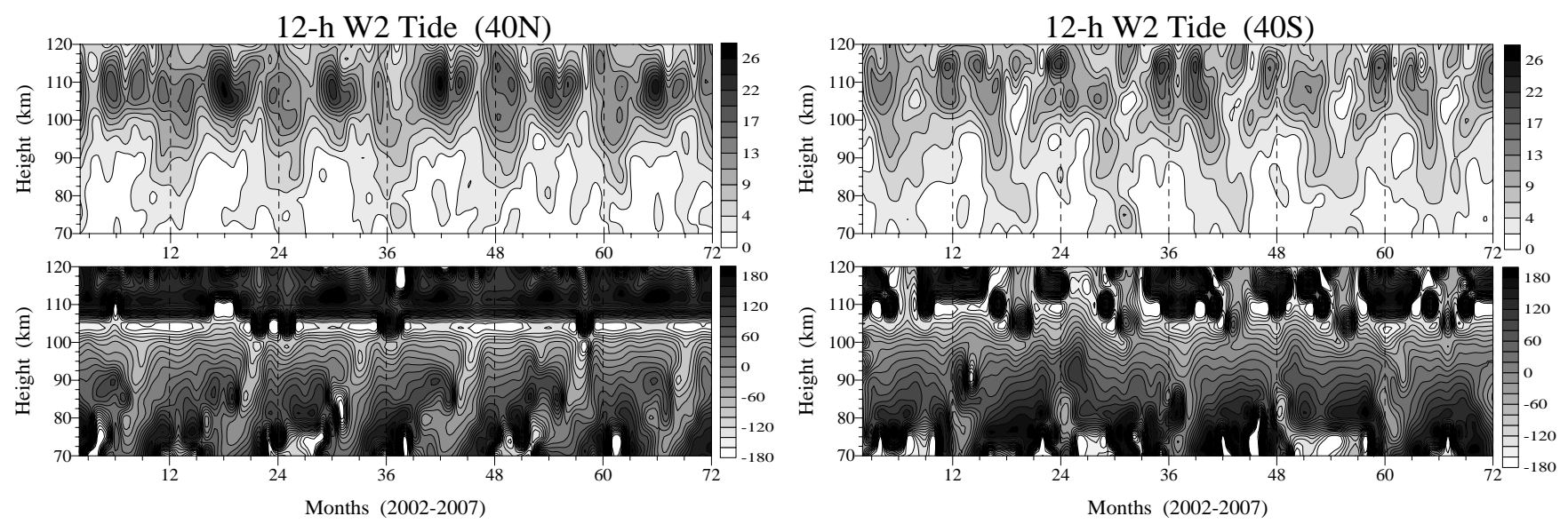

Fig. 2. Altitude-time cross sections of the tidal amplitudes in Kelvin (upper row of plots) and phases in degrees (bottom row of plots) observed at $40^{\circ} \mathrm{N}$ (left column of plots) and $40^{\circ} \mathrm{S}$ (right column of plots).

\subsection{Altitude tidal structure}

\subsubsection{Middle latitudes $\left(40^{\circ} \mathrm{N}\right.$ and $\left.40^{\circ} \mathrm{S}\right)$}

Figure 2 shows the altitude-time cross sections of the tidal amplitudes (upper row of plots) and phases (bottom row of plots) observed at $40^{\circ} \mathrm{N}$ (left column of plots) and $40^{\circ} \mathrm{S}$ (right column of plots) in the altitude range between 70 and $120 \mathrm{~km}$ (it has been already mentioned that usually the semidiurnal tidal amplitudes below $70 \mathrm{~km}$ height are too small to be meaningful along with their phases). In order to facilitate the comparison between the tidal characteristics in both hemispheres the scales are the same. The tidal amplitudes are similar in both hemispheres with a slight superiority of those from the NH. The tidal amplitude increases with increasing the height and it reaches the largest values near $110 \mathrm{~km}$ in the $\mathrm{NH}$ and near $115 \mathrm{~km}$ in the Southern Hemisphere ( $\mathrm{SH})$. At the mesospheric levels the semidiurnal tide amplifies in the winter, while in the lower thermosphere the main maximum is in summer and the secondary one - in winter (see for details the next figure). For altitudes between 70 and $90 \mathrm{~km}$ besides the winter maximum an autumn (September in the $\mathrm{NH}$ and March in the $\mathrm{SH}$ ) tidal amplification is evident as well. The phase distribution indicates that the semidiurnal tide is vertically upward propagating wave. Some seasonal variability of the vertical phase gradient (wavelength) can be distinguished from the phase plot as it is slightly larger (the wavelength is shorter) in winter than in summer. On the average, the vertical wavelength of the semidiurnal tide at both hemispheres is $\sim 35 \mathrm{~km}$ as the difference between the summer and winter wavelength is not more than $5 \mathrm{~km}$.

Figure 3 presents the monthly mean amplitudes of the semidiurnal tide at heights: $110 \mathrm{~km}$ (upper row of plots) and $90 \mathrm{~km}$ (bottom row) for $40^{\circ} \mathrm{N}$ (left column of plots) and $40^{\circ} \mathrm{S}$ (right column). The temporal variability of the tidal amplitude at $90 \mathrm{~km}$ height is dominated by annual oscilla- tion with winter maximum reaching $8-9 \mathrm{~K}$ and summer minimum of $\sim 1-2 \mathrm{~K}$ in both hemispheres. While in the SH the winter maximum at $90 \mathrm{~km}$ height is always in May that in the NH is more frequently in January-February. Whereas in the $\mathrm{SH}$ there is a signature for reducing the amplitude of the annual oscillation from 2002 to 2007 , such effect is almost absent in the NH. The tidal amplitudes at $110 \mathrm{~km}$ reveal different seasonal variability in both hemispheres. The semiannual oscillation with solstice maxima dominates the tidal amplitudes in the $\mathrm{NH}$; the main maximum is observed in the summer reaching $\sim 25-28 \mathrm{~K}$ and a secondary one in the winter with amplitudes of $\sim 15-17 \mathrm{~K}$. It is worth noting that the summer maximum is always in June and there is clear 2-year amplification of the June maximum in 2003, 2005 and 2007. A superposition of annual and semiannual variabilities with maxima in summer and autumn months and minimum in the winter dominates the behavior of the tidal amplitudes in the SH. The maxima are observed predominantly in November and March reaching amplitudes of $\sim 15-17 \mathrm{~K}$. A slight 2-year effect on the summer tidal amplitudes at $110 \mathrm{~km}$ height could be distinguished in the $\mathrm{SH}$ as some amplification is seen in 2002/2003, 2004/2005 and 2006/2007.

Figure 4 displays the average (2002-2007) seasonal behavior of the tidal amplitudes (solid line with dots for $40^{\circ} \mathrm{N}$ and with diamonds for $40^{\circ} \mathrm{S}$ ) and phases (crests for $40^{\circ} \mathrm{N}$ and empty crests for $40^{\circ} \mathrm{S}$ ) at altitudes: $110 \mathrm{~km}$ (upper row of plots) and $90 \mathrm{~km}$ (bottom row of plots). The results for the NH are shown in the left column of plots and for the $\mathrm{SH}-$ at right column of plots. The annual variability of the tidal amplitude at $90 \mathrm{~km}$ heights is well defined as the winter maximum in the SH (in May) is larger than that in the NH (January-February). Whereas the tidal phase in the NH displays a decrease in August-September, that in the SH indicates small changes between $20^{\circ}$ and $80^{\circ}$ (in local time this is between 0.7 and $2.7 \mathrm{LT}$ ). At $110 \mathrm{~km}$ height the tidal amplitude in the $\mathrm{NH}$ indicates an average main summer maximum 


\section{$40^{\circ} \mathrm{N}$}
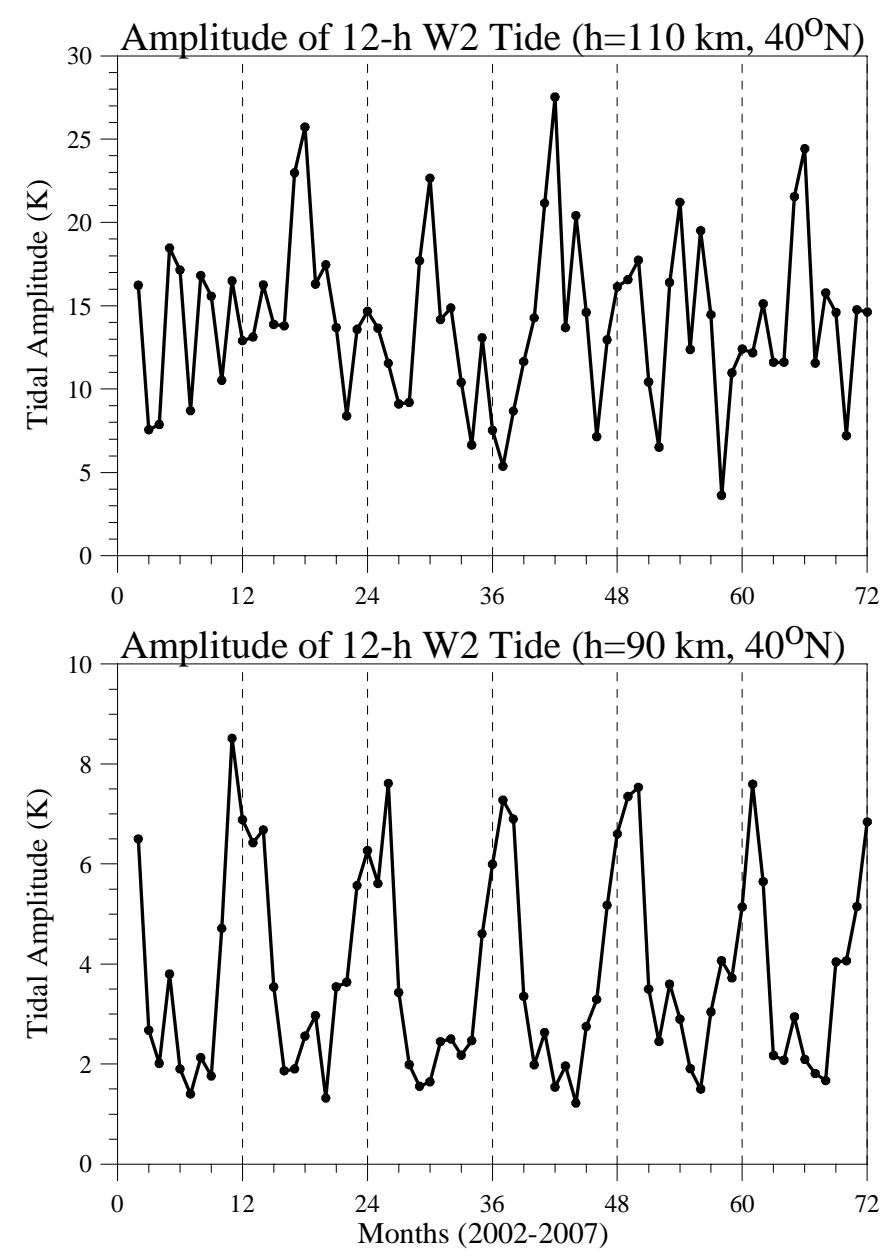

$40^{\circ} \mathrm{S}$
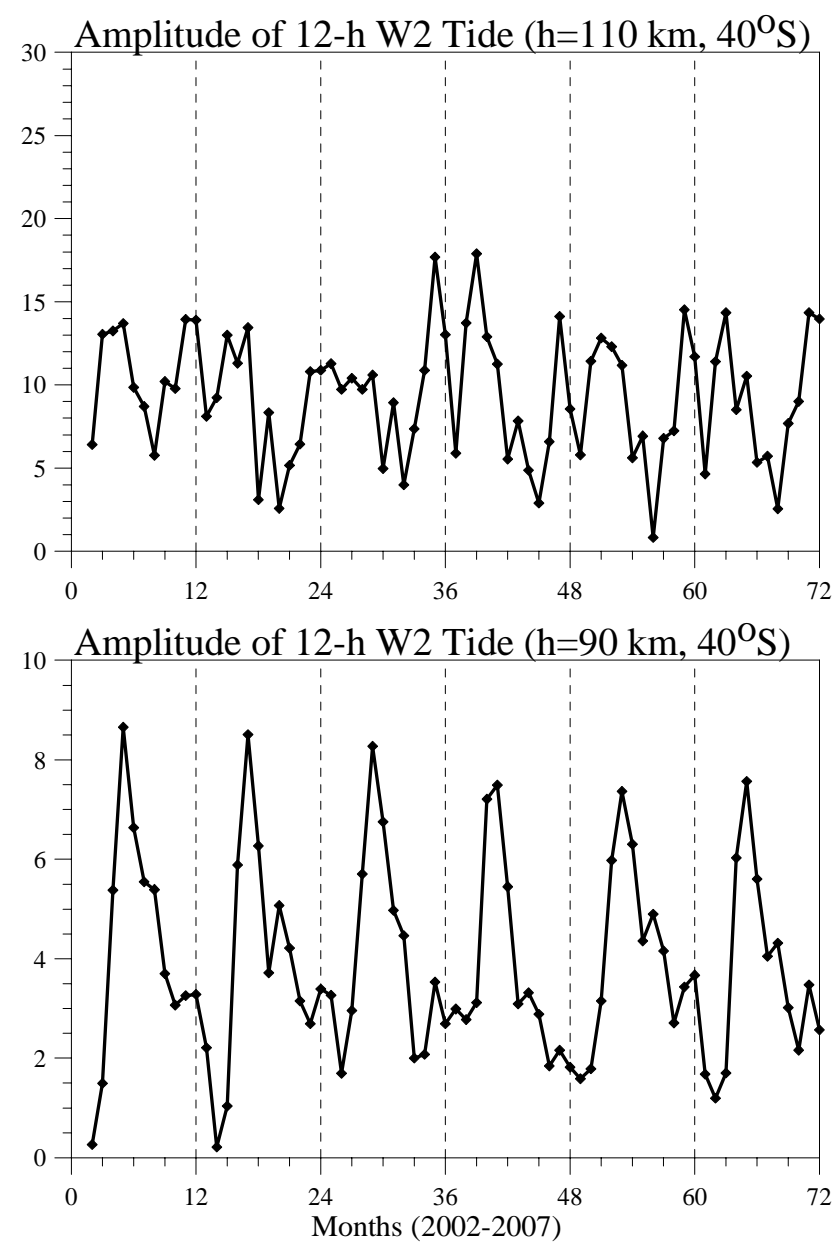

Fig. 3. Temporal distribution of the monthly mean tidal amplitudes at heights: $110 \mathrm{~km}$ (upper row of plots) and $90 \mathrm{~km}$ (bottom row of plots) for $40^{\circ} \mathrm{N}$ (left column of plots) and $40^{\circ} \mathrm{S}$ (right column).

of $23 \mathrm{~K}$ and a secondary winter one of $14-15 \mathrm{~K}$ and average equinoctial minima of 6-10 K. The average summer and autumn maxima in the $\mathrm{SH}$ are significantly smaller than the summer maximum in the $\mathrm{NH}$ reaching values of $\sim 13-15 \mathrm{~K}$; the winter minimum is also weaker than the equinoctial minima in the $\mathrm{NH}$ having amplitudes of $2-5 \mathrm{~K}$. The tidal phases at altitude of $110 \mathrm{~km}$ indicate that while in the $\mathrm{NH}$ the summer phases are larger than the winter ones (average summer phase is $180^{\circ}$ or it is $06: 00 \mathrm{LT}$ and average winter phase is $120^{\circ}$, i.e. $04: 00 \mathrm{LT}$ ) in the $\mathrm{SH}$ the opposite tendency is observed; the average summer and autumn phases are $\sim 180^{\circ}$, i.e. 06:00 LT, the winter ones are $\sim 270^{\circ}-300^{\circ}$, i.e. between 09:00 LT and 10:00 LT.

\subsubsection{Tropical latitudes $\left(20^{\circ} \mathrm{N}\right.$ and $20^{\circ} \mathrm{S}$ and equator $)$}

Figure 5 shows the altitude-time cross sections of the tidal amplitudes (upper row of plots) and phases (bottom row of plots) observed at $20^{\circ} \mathrm{N}$ (left column of plots) and $20^{\circ} \mathrm{S}$ (right column of plots). The tidal characteristics are very similar in both hemispheres. The tidal amplitudes grow rapidly with increasing the height and reach the largest values near $110 \mathrm{~km}$ in the $\mathrm{NH}$ and near $115 \mathrm{~km}$ in the SH. On the average, the migrating semidiurnal tide in the SH is slightly stronger than that in the NH. The amplitude difference between the largest amplitudes from both hemispheres however does not exceed $2 \mathrm{~K}$. In both hemispheres the semidiurnal tide amplifies significantly between May and August. The phase structure indicates that the semidiurnal tide is vertically upward propagating wave. The seasonal variability of the vertical phase gradient (wavelength) can be distinguished easily from the phase plot and it is stronger than that in the middle latitudes (see Fig. 2, bottom plots). The phase gradient is larger (the wavelength is shorter) during the winter than that in summer in both hemispheres. This point will be considered more closely later. 

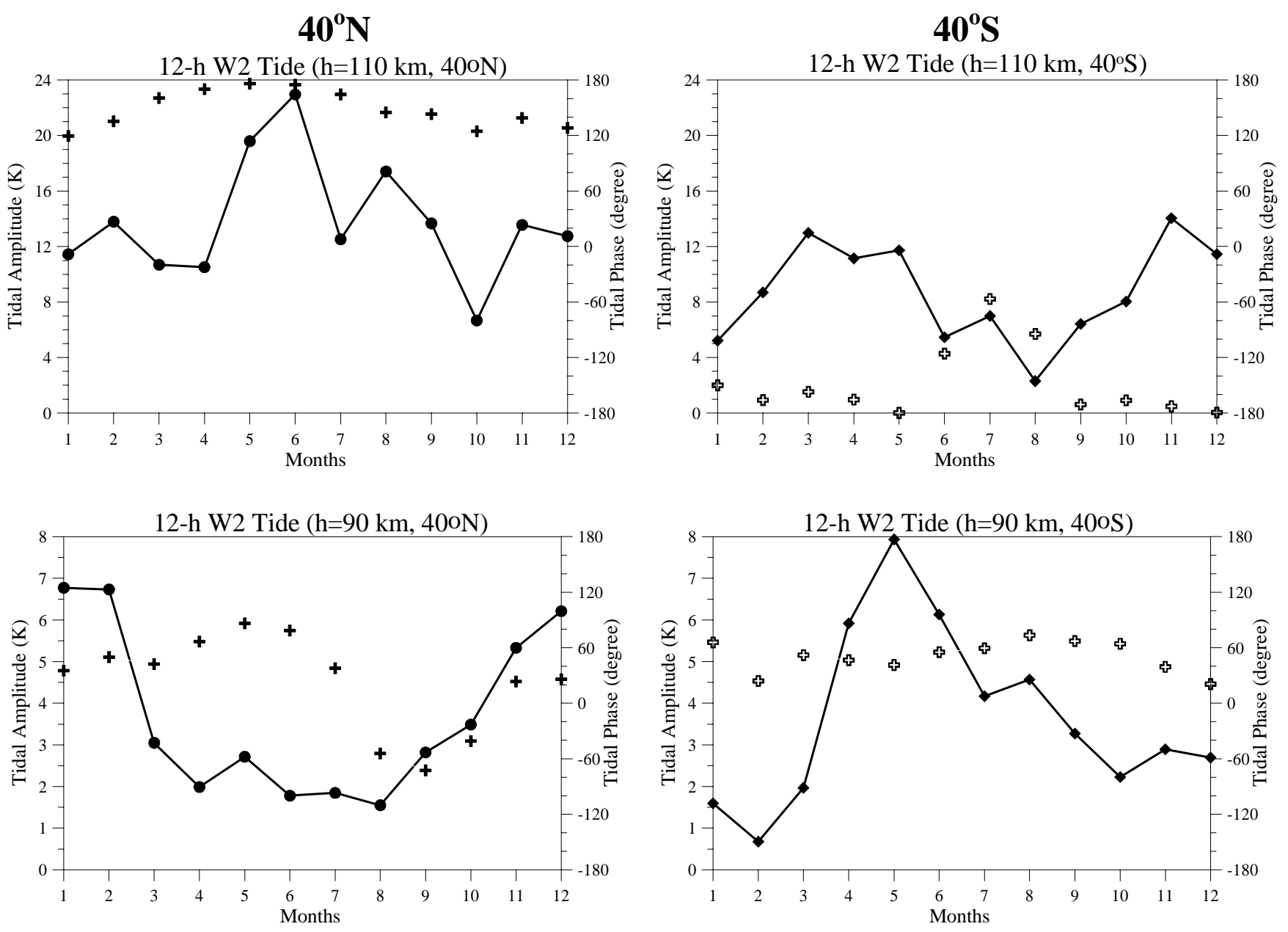

Fig. 4. Average (2002-2007) seasonal behavior of the tidal amplitudes (solid line with dots for $40^{\circ} \mathrm{N}$ and with diamonds for $40^{\circ} \mathrm{S}$ ) and phases (crests for $40^{\circ} \mathrm{N}$ and empty crests for $40^{\circ} \mathrm{S}$ ) at altitudes: $110 \mathrm{~km}$ (upper row of plots) and $90 \mathrm{~km}$ (bottom row of plots); the results for the $\mathrm{NH}$ are shown in the left column of plots and for the $\mathrm{SH}-$ right column of plots.

Figure 6 presents the monthly mean amplitudes of the semidiurnal tide at heights: $110 \mathrm{~km}$ (upper row of plots) and $90 \mathrm{~km}$ (bottom row of plots) for $20^{\circ} \mathrm{N}$ (left column of plots) and $20^{\circ} \mathrm{S}$ (right column). The temporal variability of the tidal amplitudes at both heights is dominated by a superposition of annual and semiannual variabilities. Whereas the annual behavior is predominant at the upper level the semiannual one is at the lower height. The NH tide reveals remarkable seasonal behavior at $110 \mathrm{~km}$ height with repeatable each year maxima in May-June and August-September. It is worth noting that at height of $115 \mathrm{~km}$ where the migrating semidiurnal tide in the $\mathrm{SH}$ reaches maximum it also reveals remarkable seasonal behavior with repeatable each year maxima in May and August. The monthly mean amplitudes of the semidiurnal tide at height of $115 \mathrm{~km}$ in the SH are shown on the right upper plot of Fig. 6 with dash line. However, while the main maximum in the $\mathrm{NH}$ is that in AugustSeptember, in the SH is that in May.
Figure 7 displays the average (2002-2007) seasonal behavior of the tidal amplitudes (solid line with dots for $20^{\circ} \mathrm{N}$ and with diamonds for $20^{\circ} \mathrm{S}$ ) and phases (crests for $20^{\circ} \mathrm{N}$ and empty crests for $20^{\circ} \mathrm{S}$ ) at altitudes: $110 \mathrm{~km}$ (upper row of plots) and $90 \mathrm{~km}$ (bottom row of plots). As before the results for the $\mathrm{NH}$ are shown in the left column of plots and for the $\mathrm{SH}$ - right column of plots. The seasonal courses of the tidal amplitude at both levels indicate high degree of similarity but the tidal amplitudes have very different magnitudes. On the average the tidal amplitudes at $110 \mathrm{~km}$ height are nearly a factor of 5 larger than those at $90 \mathrm{~km}$. The tidal phases at both heights in the $\mathrm{NH}$ have similar seasonal courses as the phases between May and September are smaller than those between November and March; at $110 \mathrm{~km}$ height they are respectively $\sim 150^{\circ}(05: 00 \mathrm{LT})$ and $\sim 210^{\circ}(07: 00 \mathrm{LT})$, while at the $90 \mathrm{~km}$ the phases are $0^{\circ}(00: 00 \mathrm{LT})$ and $-120^{\circ}(08: 00 \mathrm{LT})$. The seasonal courses of the tidal phase in the SH are also similar at both heights however the May-September phases are larger 

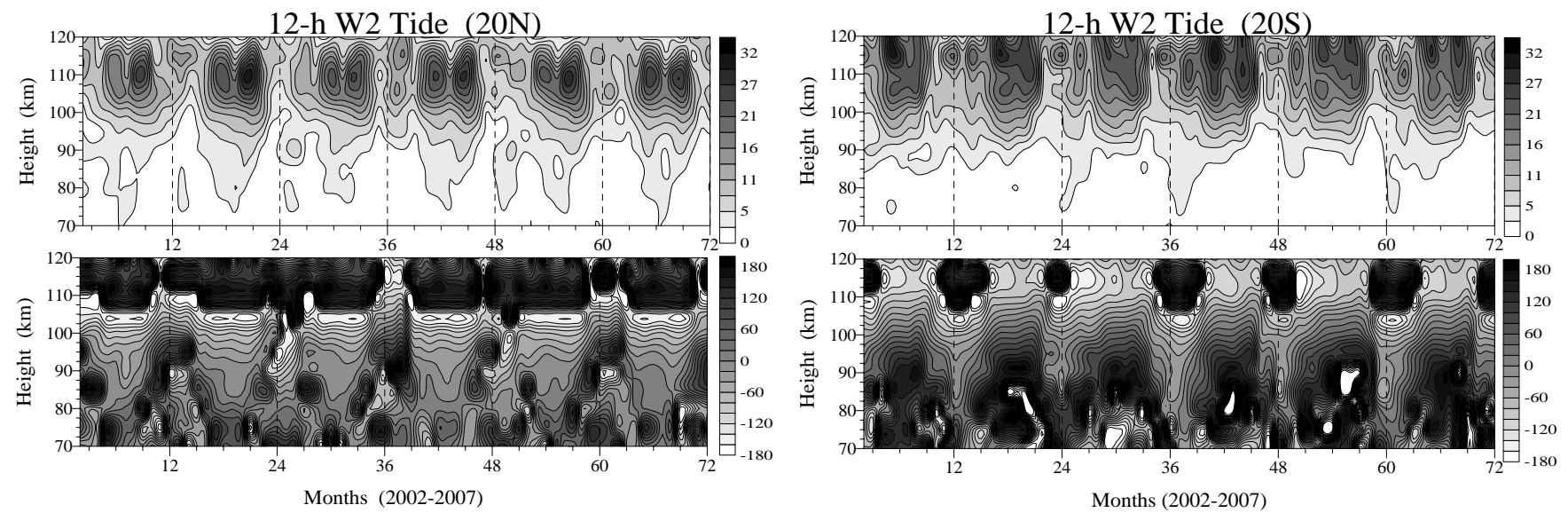

Fig. 5. Altitude-time cross sections of the tidal amplitudes (upper row of plots) and phases (bottom row of plots) observed at $20^{\circ} \mathrm{N}$ (left column of plots) and $20^{\circ} \mathrm{S}$ (right column of plots).

than those of November-March; at $110 \mathrm{~km}$ height they are respectively: $\sim-90^{\circ}(09: 00 \mathrm{LT})$ and $\sim-180^{\circ}(06: 00 \mathrm{LT})$ and at $90 \mathrm{~km}$, respectively $\sim 150^{\circ}(05: 00 \mathrm{LT})$ and $30^{\circ}(01: 00 \mathrm{LT})$.

Figure 8 shows the altitude-time cross sections of the amplitude in Kelvin (upper plot) and phase in degrees (bottom plot) of the semidiurnal temperature tide over the equator. This is the region where the migrating semidiurnal tide reaches the smallest amplitudes in the lower thermosphere comparing with those at $20^{\circ}(30 \mathrm{~K})$ and $40^{\circ}(26 \mathrm{~K})$. Over the equator the tide amplifies significantly above $105 \mathrm{~km}$ height and its amplitude reaches $21 \mathrm{~K}$. Near altitude of $80 \mathrm{~km}$ the semidiurnal tide is present almost the entire year but its seasonal variability does not indicate a regular behavior. It appears that the observed semidiurnal tide undergoes some decay between $\sim 80 \mathrm{~km}$ and $\sim 105 \mathrm{~km}$, however a slight increase of the tide is observed between 95 and $100 \mathrm{~km}$. Below $80 \mathrm{~km}$ height there is a weak amplification of the tide during the boreal winter months. The altitude phase structure (bottom plot) reveals vertically upward propagating semidiurnal tide during the entire year only above $95-100 \mathrm{~km}$ height. In most cases when the semidiurnal tide has statistically significant amplitudes is also vertically upward propagating wave above $75-80 \mathrm{~km}$ height but not in the boreal winter.

The above results clearly indicated that the strongest migrating semidiurnal tide is observed in the tropical lower thermosphere where the largest monthly mean tidal amplitude during the considered period of time reaches $32 \mathrm{~K}$. The phase plots of Fig. 5 revealed quite well evident seasonal dependence of the vertical wavelength. Therefore it is worth studying this topic more closely. Figure 9 presents the average (2002-2007) tidal phases for the altitude range between 90 and $115 \mathrm{~km}$ marked by different colors (black for $90 \mathrm{~km}$; purple for $95 \mathrm{~km}$, blue for $100 \mathrm{~km}$, red for $105 \mathrm{~km}$, magenta for $110 \mathrm{~km}$ and green for $115 \mathrm{~km}$ ) for $20^{\circ} \mathrm{N}$ (left plot) and $20^{\circ} \mathrm{S}$ (right plot). In order to facilitate the comparison the scales at both plots are the same. In general, the vertical phase gradients in the $\mathrm{NH}$ are larger than those in the $\mathrm{SH}$, i.e. the tidal vertical wavelengths in the $\mathrm{NH}$ are shorter than those in the SH. Additionally, the vertical phase gradients are larger in winter than in summer at both hemispheres defining in this way shorter vertical wavelengths in the winter than in the summer. The detailed analysis reveals that while in the $\mathrm{NH}$ the summer and winter vertical wavelengths are respectively $\sim 38-40 \mathrm{~km}$ and $25-28 \mathrm{~km}$, those for the SH are $\sim 43-47 \mathrm{~km}$ and $\sim 30-33 \mathrm{~km}$. The vertical wavelengths in the equinoxes are usually between those in the summer and winter. We note however that the vertical wavelengths in February at $20^{\circ} \mathrm{N}$ and in October at $20^{\circ} \mathrm{S}$ are longer than those observed in summer reaching $\sim 50-53 \mathrm{~km}$.

\subsection{Altitude-latitude tidal structure}

The left column of plots in Fig. 10a shows the average for the considered 6 years (2002-2007) altitude-latitude crosssections of the tidal amplitudes (upper plot) and phases (bottom plot) for June, while the right column of plots - the same but for December. Again only the altitude range between 70 and $120 \mathrm{~km}$ is considered because the tidal amplitudes below $70 \mathrm{~km}$ are too small to be meaningful along with their phases. In general a symmetric nature of the SABER tidal amplitudes is visible in June solstice with a maximum reaching $\sim 27 \mathrm{~K}$. While the summer maximum is located at latitude of $\sim 30^{\circ}$ and altitude near $110 \mathrm{~km}$ the winter one is near latitude of $20^{\circ}$ and altitude of $\sim 115 \mathrm{~km}$. The phase distribution shows a downward tilting of phase lines as one progresses from the summer to winter hemisphere. In this case a clear vertical wavelength is difficult to be identified from the phase plot. The altitude versus latitude distribution of the tidal amplitude in December (upper right plot) indicates more complicated structure than that in June. There are three amplitude maxima in the lower thermosphere: (i) summer maximum $(\sim 21 \mathrm{~K})$ located near latitude of $30^{\circ} \mathrm{S}$ and altitude 
$20^{\circ} \mathrm{N}$
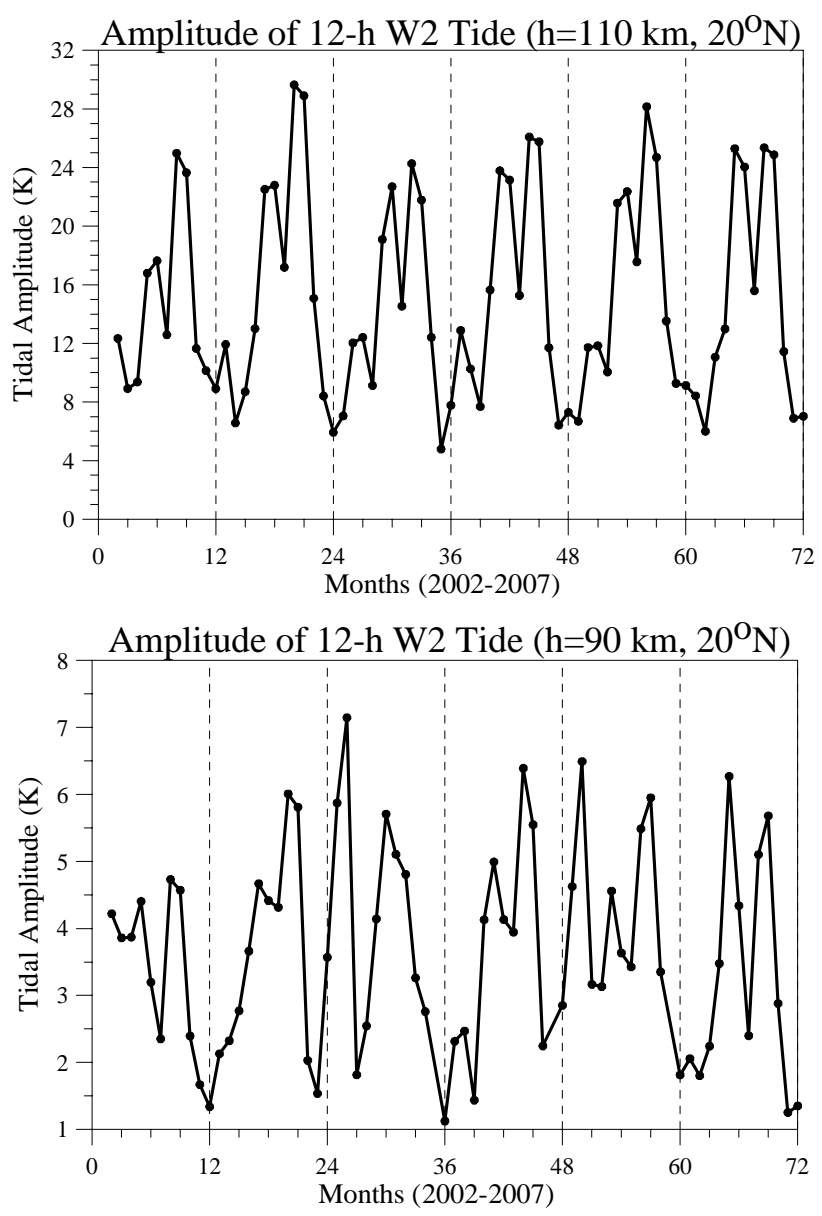

$20^{\circ} \mathrm{S}$
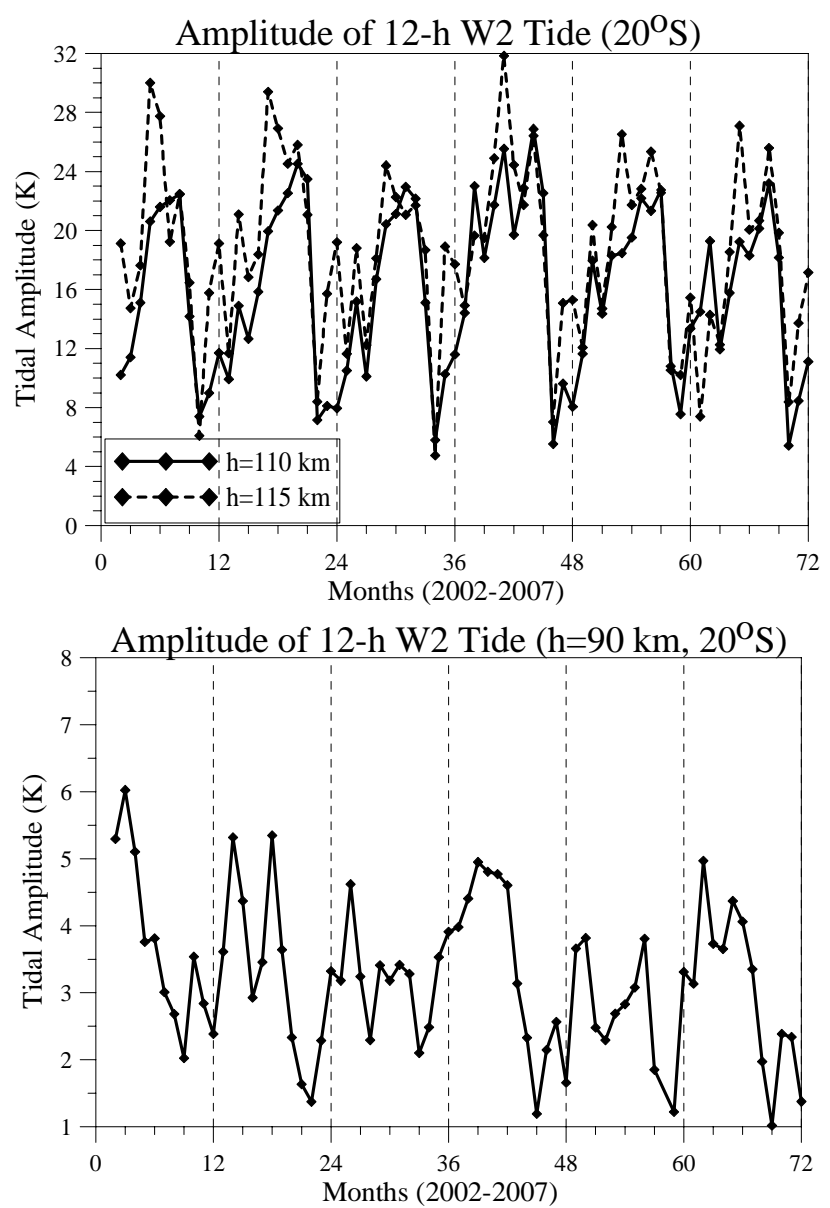

Fig. 6. Temporal distribution of the monthly mean tidal amplitudes at heights: $110 \mathrm{~km}$ (upper row of plots) and $90 \mathrm{~km}$ (bottom row) for $20^{\circ} \mathrm{N}$ (left column of plots) and $20^{\circ} \mathrm{S}$ (right column of plots) shown by solid lines; the monthly mean tidal amplitudes at $115 \mathrm{~km}$ height at $20^{\circ} \mathrm{S}$ are displayed by dash line in the upper right plot.

of $115 \mathrm{~km}$, (ii) equatorial $\left(0-10^{\circ} \mathrm{N}\right)$ maximum of $\sim 16 \mathrm{~K}$ located at $115 \mathrm{~km}$ height, and (iii) winter maximum $(\sim 14 \mathrm{~K})$ located at latitude of $40^{\circ} \mathrm{N}$ and centered between 100 and $110 \mathrm{~km}$ altitudes. Similarly to the June solstice the phase distribution in December (bottom right plot) shows a downward tilting of phase lines as one progresses from the summer to winter hemisphere. Above $75 \mathrm{~km}$ height in the winter hemisphere a vertical wavelength of $\sim 35 \mathrm{~km}$ can be seen at $40^{\circ} \mathrm{N}$ from the phase plot.

The left column of plots in Fig. 10b shows the average for the considered 6 years altitude-latitude cross-sections of the tidal amplitudes (upper plot) and phases (bottom plot) for March, while the right column of plots - the same but for October. In general, a symmetric nature of the lower thermospheric tidal amplitudes is visible in both months. The March amplitude maxima $(\sim 16-17 \mathrm{~K})$ are located at latitudes near $\pm 30^{\circ}$ and altitudes of $\sim 115 \mathrm{~km}$ in the $\mathrm{SH}$ and $\sim 110 \mathrm{~km}$ in the NH. The phase distribution in March (bottom left plot) reveals a downward tilting of phase lines as one progresses from the $\mathrm{NH}$ to the $\mathrm{SH}$. Above $75 \mathrm{~km}$ height in the $\mathrm{NH}$ a vertical wavelength of order $35 \mathrm{~km}$ can be seen in the middle latitudes. The October amplitude maxima in the lower thermosphere are located at: (i) $\pm(20-30)^{\circ}$ and at $105 \mathrm{~km}$ height and (ii) over the equator with an amplitude rapidly growing with the height above $110 \mathrm{~km}$ altitude. The tropical October amplitudes are weaker than those in March; they are $\sim 15 \mathrm{~K}$ and $\sim 10-11 \mathrm{~K}$ in the $\mathrm{NH}$ and $\mathrm{SH}$ hemispheres respectively. At mesosphere levels (70-95 km) two weak equatorial maxima can be seen in both equinoctial months. The phase distribution in October (bottom right plot) reveals a downward tilting of phase lines as one progresses from the $\mathrm{SH}$ to the $\mathrm{NH}$. Above $80 \mathrm{~km}$ height in the SH a vertical wavelength of order $35 \mathrm{~km}$ can be seen in the middle latitudes.

The seasonal altitude-latitude structure of the tidal amplitudes and phases indicates that different Hough modes contribute to the tidal composition during different seasons and 

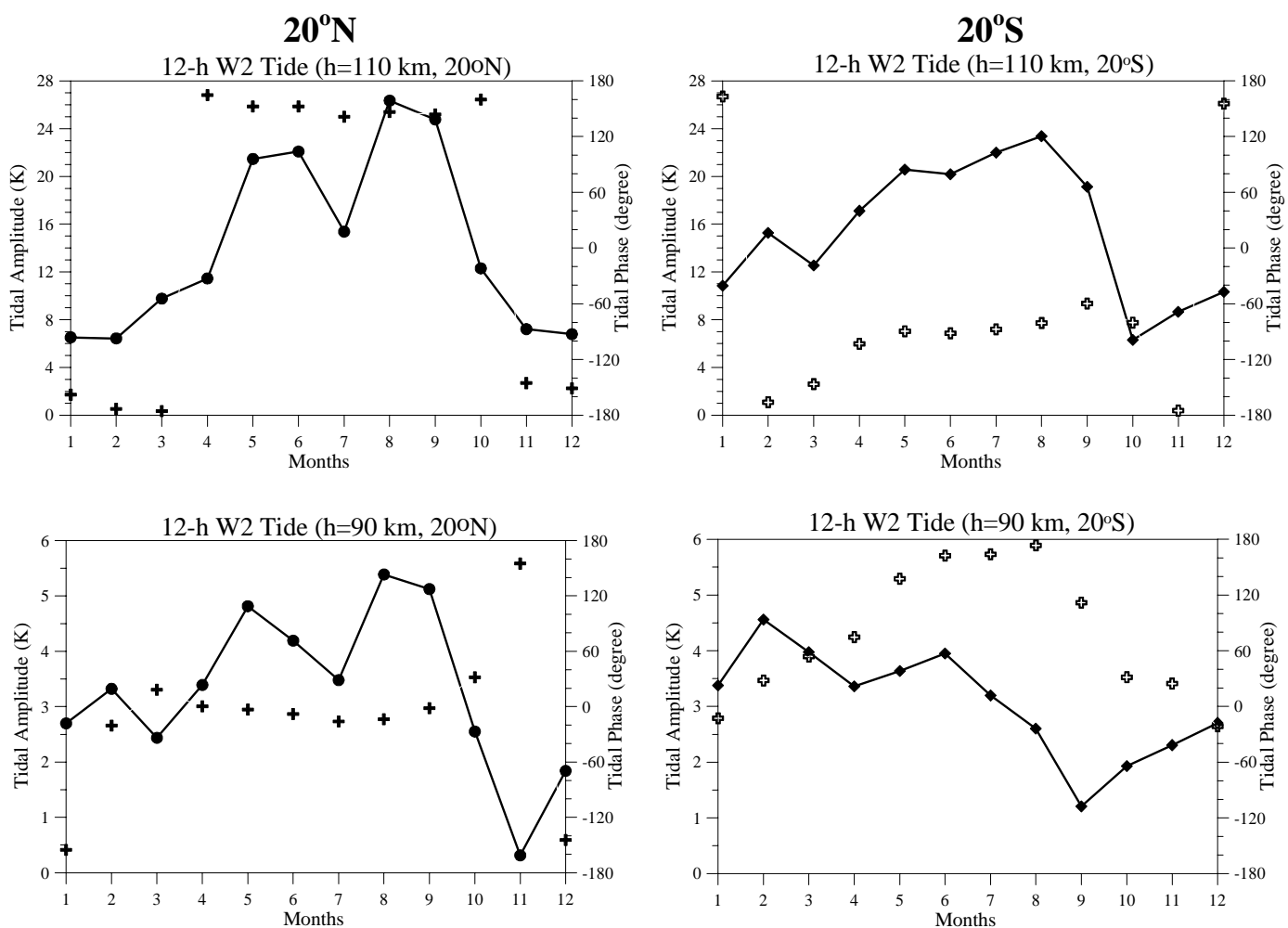

Fig. 7. Average (2002-2007) seasonal behavior of the tidal amplitudes (solid line with dots for $20^{\circ} \mathrm{N}$ and with diamonds for $20^{\circ} \mathrm{S}$ ) and phases (crests for $20^{\circ} \mathrm{N}$ and empty crests for $20^{\circ} \mathrm{S}$ ) at altitudes: $110 \mathrm{~km}$ (upper row of plots) and $90 \mathrm{~km}$ (bottom row); the results for the $\mathrm{NH}$ are shown in the left column of plots and for the $\mathrm{SH}$ - right column of plots.

altitudes. The vertical wavelength of the SABER temperature tide revealed seasonal dependence (larger in summer than in winter) but on the average it ranges between 25 $30 \mathrm{~km}$ and $45-47 \mathrm{~km}$ and does not exceed $55 \mathrm{~km}$ particularly in February and October. This means that the contribution of the first symmetric $(2,2)$ and antisymmetric $(2,3)$ modes, whose vertical wavelengths are larger than $75-80 \mathrm{~km}$ (Forbes, 1995), is small or limited only to a given altitude range. The symmetric $(2,4)$ and antisymmetric $(2,5)$ modes seem to have a main effect during June solstice (left plot of Fig. 10a), while in December (right plot of Fig. 10a) the contribution of the symmetric $(2,6)$ mode is evident as well. During equinoxes the migrating semidiurnal tide most probably is composed mainly by symmetric $(2,4)$ and $(2,6)$ modes (Fig. 10b).

\subsection{Interannual variability of the tidal amplitude}

It has been found that the amplitude of the $40^{\circ} \mathrm{N}$ semidiurnal tide in the summer lower thermosphere ( $110 \mathrm{~km}$ height) is modulated by the 2-year variation (see upper left plot in Fig. 3). The 2-year effect has been particularly visible on the June maximum amplifying it during 2003, 2005 and 2007. This feature could be due to modulation by the quasi-biennial oscillation (QBO) of the stratosphere zonal mean flow as the tide propagates from the tropospheric and stratospheric sources to the lower thermosphere. Hagan et al. (1992) reported that the QBO of stratospheric ozone does not affect the semidiurnal tidal forcing. In this modeling study however the QBO signature in the upward propagating 12-h tide during January has been largely evident in the neutral wind at high mesospheric latitudes.

Recently Huang et al. (2006, 2008) have examined the QBO in the stratosphere-mesosphere SABER/TIMED zonal mean temperature and ozone and its effect on the mesospheric temperature diurnal tide. The authors calculated the QBO variability of the zonal mean temperature by assuming that the period of QBO is 24 or 26 months. Then, by a least squares fitting procedure performed on the data from January 2002 to December 2003, in the case for 24-month QBO period, or from January 2002 to February 2004, in the case for 26-month QBO period, the authors defined the mean amplitude and phase of the QBO and reconstructed the QBO temperature variability.

In this study we apply a similar approach, however first we define the mean QBO period using the monthly mean QBO index at $30 \mathrm{hPa}$ and $50 \mathrm{hPa}$ pressure levels downloaded from the NOAA Climate Prediction Center (http://www.cpc.ncep. noaa.gov/) for the period of time between January 1979 and July 2008. For both pressure levels we found that the period 

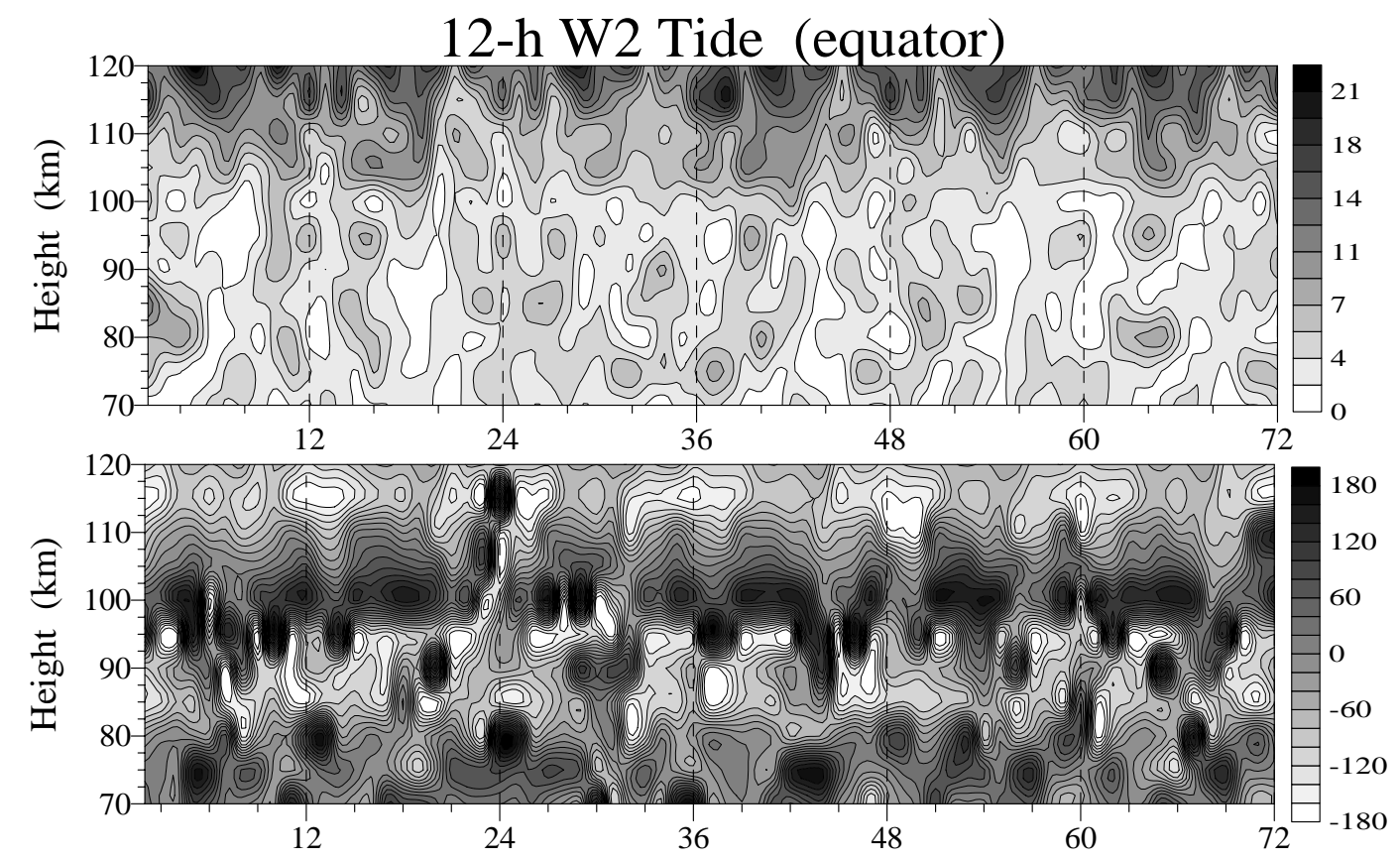

Months (2002-2007)

Fig. 8. Altitude-time cross sections of the tidal amplitude (upper plot) and phase (bottom plot) of the semidiurnal tide over the equator.
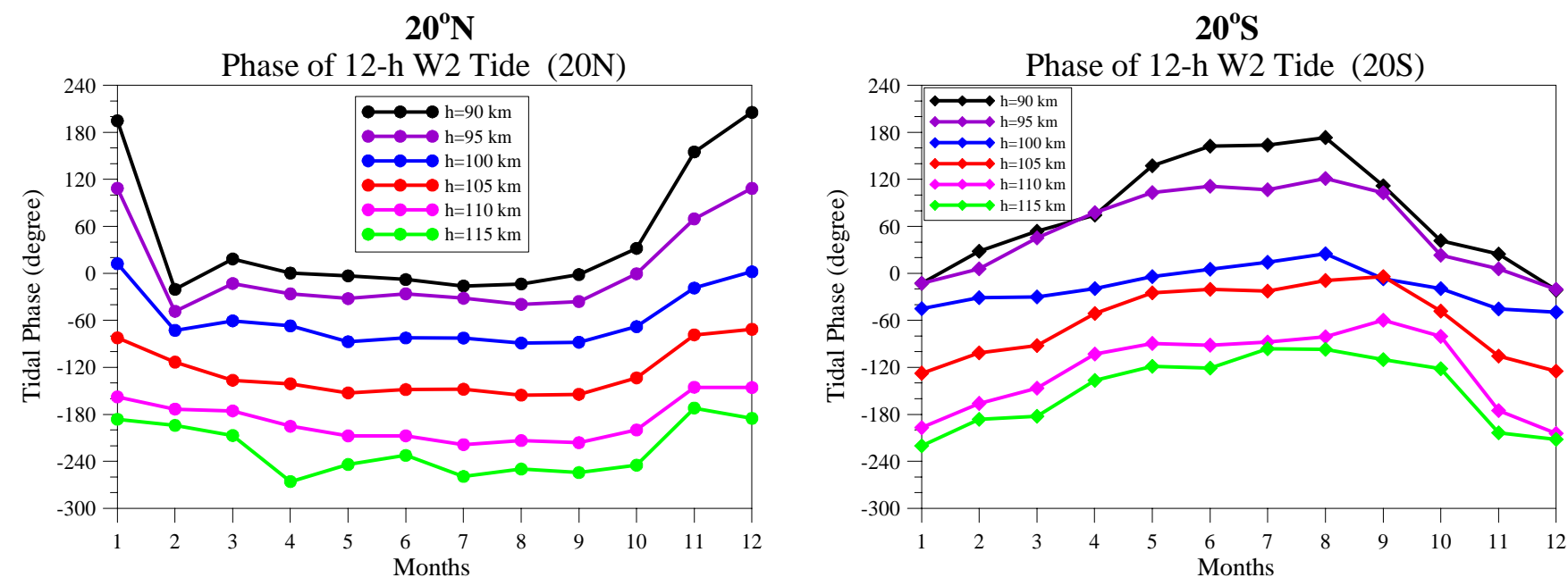

Fig. 9. Average (2002-2007) monthly tidal phases for the altitude range between 90 and $115 \mathrm{~km}$ marked by different colors (black for $90 \mathrm{~km}$; purple for $95 \mathrm{~km}$, blue for $100 \mathrm{~km}$, red for $105 \mathrm{~km}$, magenta for $110 \mathrm{~km}$ and green for $115 \mathrm{~km}$ ) for $20^{\circ} \mathrm{N}$ (left plot) and $20^{\circ} \mathrm{S}$ (right plot).

of QBO is 28 months. We spectrally analyzed also the data only for the considered in this study interval, i.e. January 2002-December 2007, and obtained the same result. Then by performing the fitting technique on the monthly mean time series of the zonal mean temperature for the entire time interval (2002-2007) we derive the average (for the studied 6 years) amplitude and phase of the QBO which are used for generating the QBO variability of the zonal mean temperature. The analogous procedure is done with the monthly mean amplitudes of the semidiurnal tide. In this case we obtain the QBO modulation of the semidiurnal tidal amplitude.

The bottom plot of Fig. 11 presents the QBO variability in the zonal mean temperature at $40^{\circ} \mathrm{N}$. The strongest QBO maximum is located in the lower thermosphere, between 110 and $120 \mathrm{~km}$ height, with an amplitude reaching $\sim 3.5 \mathrm{~K}$. The positive zonal mean temperature perturbations are visible in 2003,2005 and in the second half of 2007 , i.e. when the June semidiurnal tidal maximum is amplified. The lower 

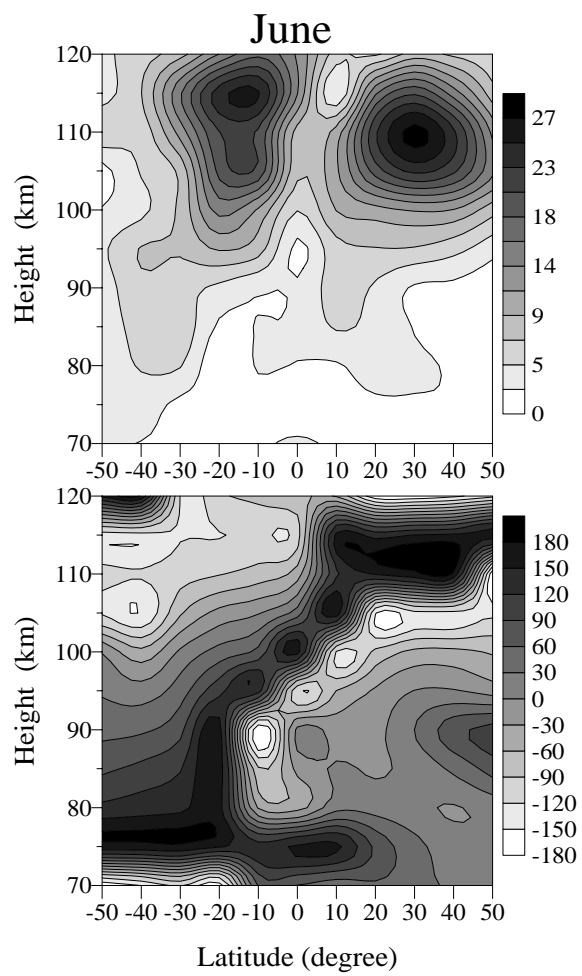
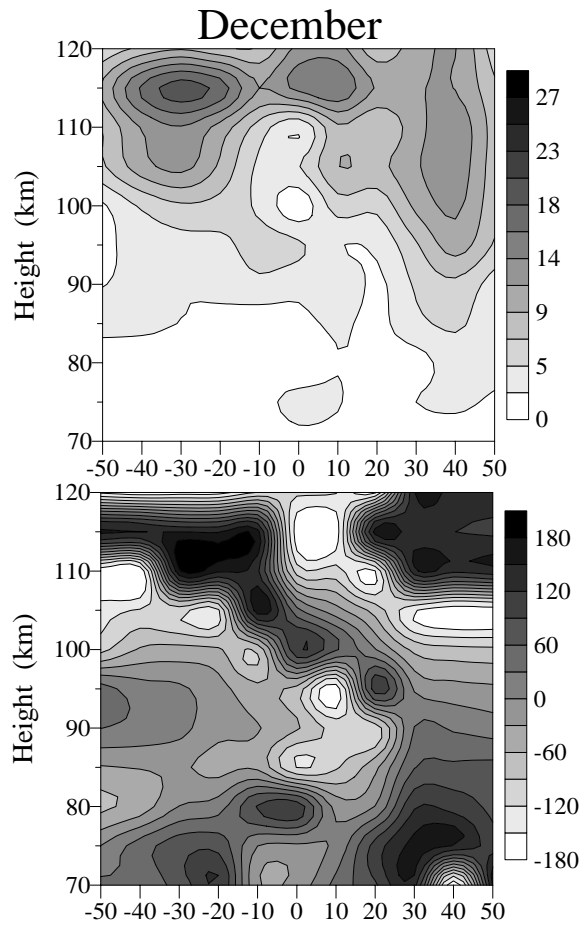

Latitude (degree)

Fig. 10a. Average (2002-2007) altitude-latitude cross-sections of the tidal amplitudes (upper row of plots) and phases (bottom row of plots) for June (left column of plots) and December (right column of plots).
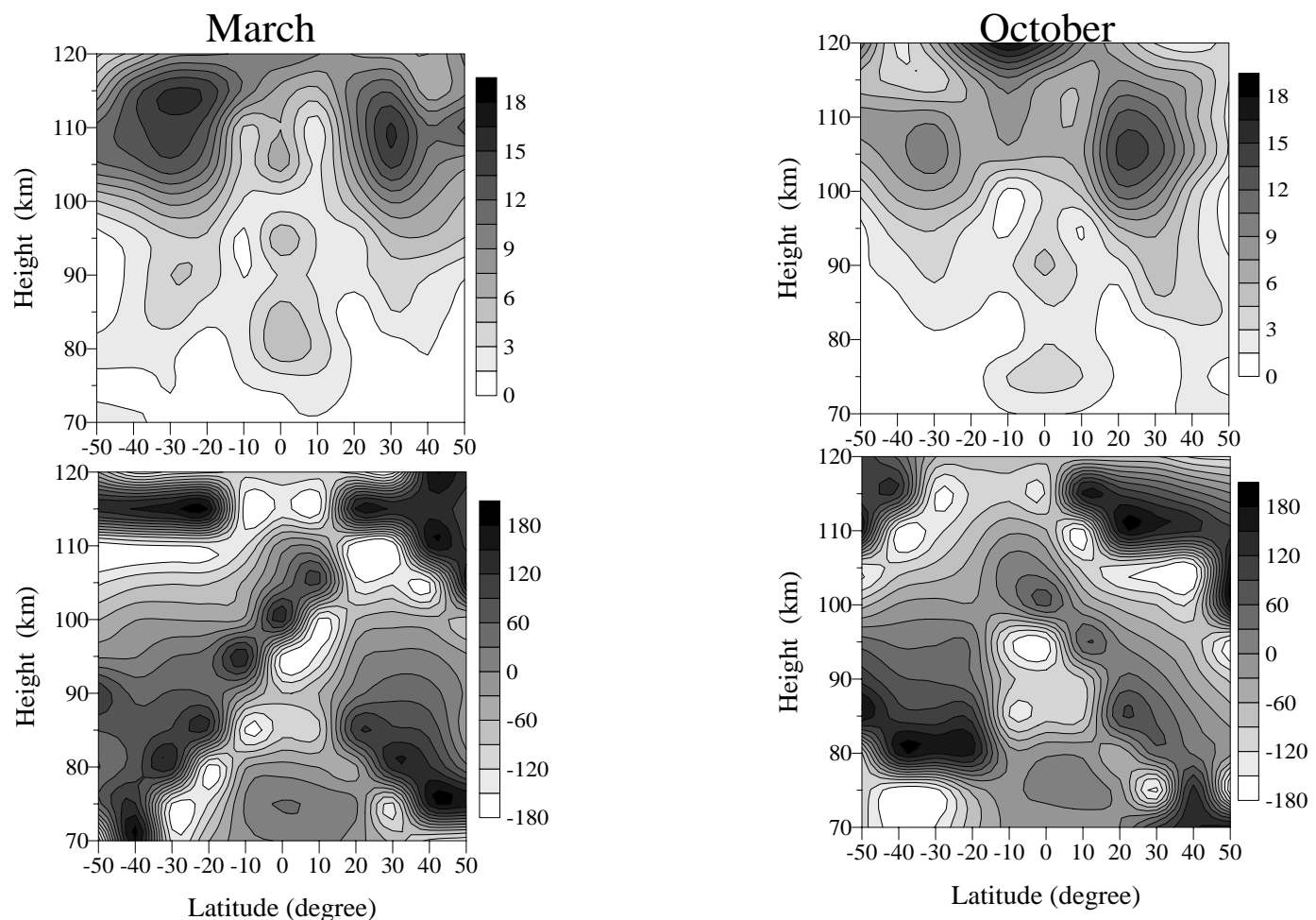

Fig. 10b. The same as Fig. 11a, but for March (left column of plots) and October (right column of plots). 
mesospheric $(\sim 70 \mathrm{~km})$ and stratospheric $(\sim 20$ and $\sim 40 \mathrm{~km})$ maxima are weaker than that in the lower thermosphere. In general, lower thermospheric QBO maximum is almost out of phase with those in the lower mesosphere $(\sim 70 \mathrm{~km})$ and the lower stratosphere $(\sim 20 \mathrm{~km})$.

The upper plot of Fig. 11 displays the QBO modulation of the semidiurnal tidal amplitude at $40^{\circ} \mathrm{N}$. The mean QBO variability of the tidal amplitude reaches peak of $\sim 2 \mathrm{~K}$. The strongest effect is observed in the lower thermosphere, centered at $110 \mathrm{~km}$ height, where the semidiurnal tide itself maximizes. The positive tidal modulations coincide with the positive phase of the lower thermospheric temperature QBO. We note also that the QBO modulation of the semidiurnal tidal amplitude at $50^{\circ} \mathrm{N}$ is even stronger than that at $40^{\circ} \mathrm{N}$ having average amplitude of $\sim 2.5 \mathrm{~K}$ (not shown result). This analysis indicates that the interannual variability of the semidiurnal tide observed in the $\mathrm{NH}$ lower thermosphere at midlatitudes is at least partly generated by the QBO. It is worth noting that in contrast to the modeling study of Hagan et al. (1992) where the QBO signature has been evident in the January 12-h tide the SABER result revealed QBO oscillation well seen in the June semidiurnal tide.

The same analysis has been done on the semidiurnal tidal amplitudes at $40^{\circ} \mathrm{S}$. The mean QBO variability of the tidal amplitude reaches peak only of $\sim 1-1.2 \mathrm{~K}$ (not shown result), i.e. two times smaller than that at $40^{\circ} \mathrm{N}$. The strongest effect is again found in the lower thermosphere, centered at $\sim 110 \mathrm{~km}$ height, however a secondary amplification, near $95 \mathrm{~km}$ height, is also seen during the austral summers of 2002/2003, 2004/2005 and 2006/2007.

\section{Discussion and summary}

In this paper we have presented the global spatial (altitude and latitude) structure and temporal variability, particularly seasonal behavior, of the migrating semidiurnal tide seen in full 6 years (January 2002-December 2007) observations of the kinetic temperature measured by the SABER instrument on the TIMED satellite. This topic is worthy of special attention because tides in the upper MLT are the most profound and persistent feature of the large scale dynamics there. The tidal results have been obtained by a new analysis method where the tides (migrating and nonmigrating) and the planetary waves (zonally travelling, zonally symmetric and stationary) are simultaneously extracted from the satellite data. The detailed description of this method has been presented in the complimentary study of the migrating diurnal tide reported by Mukhtarov et al. (2009) and here it was only briefly summarized. The method for defining the reference noise level for the tidal waves has been briefly mentioned as well.

The obtained consistent picture for the spatial tidal structure and the repeating seasonal variability during all considered six years is a clear recommendation for the validity of this new method not only to derive successfully plane-
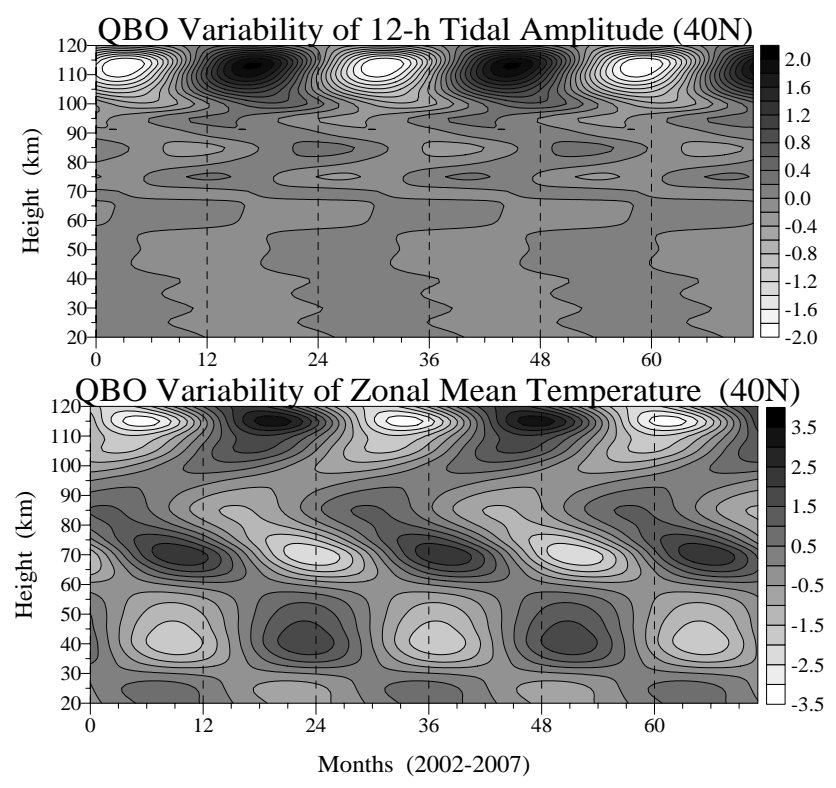

Fig. 11. Semidiurnal tidal amplitude (upper plot) and zonal mean temperature (bottom plot) variations for QBO period of 28 months plotted versus height and months for period of time between January 2002 and December 2007.

tary waves from the satellite measurements (Pancheva et al., 2009a, b), but atmospheric tides as well. It has been already mentioned that some results for the migrating semidiurnal tide based on much shorter period of SABER measurements were reported by Zhang et al. (2006). In comparing the tidal results from this study with those of the above mentioned authors we have to keep in mind the peculiarities of each data analysis method. Zhang et al. (2006) used 120-day time segments of data (centered on the 15th of the month) for extracting the tides which is two times longer than that used in this study. This means that we expect in advance our monthly mean tidal amplitudes to be larger than those derived by Zhang et al. (2006). In the case when the tidal phase is stable both results should be similar. For example, Zhang et al. (2006) for August 2004 (their Fig. 4b) derived maximum tidal amplitude of $\sim 16 \mathrm{~K}$ while we obtained the same latitude versus height tidal amplitude distribution but the maximum tidal amplitude was $\sim 24 \mathrm{~K}$ (not shown result).

Recently Forbes et al. (2008) investigated seasonal and interannual variability of the migrating and nonmigrating tides at altitudes only between 100 and $116 \mathrm{~km}$ seen in SABER/TIMED temperatures which could have effect on the ionospheric dynamo. The latitude structure of the migrating semidiurnal tidal amplitude at height of $100 \mathrm{~km}$ during 20022006 has been reported there (their Fig. 1, middle plot). The comparison with the tidal results from this study indicated a high degree of similarity because the both methods use a 60day time window for extracting the waves. The authors found also a $\pm 10-15 \%$ QBO variation of the tidal amplitude in both 
hemispheres. The result of this study however revealed two times stronger QBO variability of the tidal amplitude in the midlatitude $\mathrm{NH}$ (with an amplitude of $\sim 2-2.5 \mathrm{~K}$ ) than that in the $\mathrm{SH}$ (with an amplitude of $\sim 1-1.2 \mathrm{~K}$ ).

Recently on the basis of Na lidar observations over full diurnal cycles from May 2002 to April 2006 Yuan et al. (2008) investigated the seasonal variations of the semidiurnal tidal characteristics over Fort Collins, Colorado $\left(41^{\circ} \mathrm{N}, 105^{\circ} \mathrm{W}\right)$ in the altitude range between 80 and $100 \mathrm{~km}$. The comparison with the results from this study for middle latitudes, $40^{\circ} \mathrm{N}$, reveals the follows: (i) the largest tidal amplitudes derived from the lidar and SABER temperatures have average magnitudes of 12 and $\sim 13 \mathrm{~K}$ (see upper right plot of Fig. 10a) respectively observed in winter (December); (ii) in summer, particularly in July, the lidar semidiurnal tide is the weakest, while the SABER tide in summer shows a secondary amplification reaching amplitudes of $\sim 10-11 \mathrm{~K}$ at $h=100 \mathrm{~km}$ in June-July (see the upper left plot of Fig. 2); the weakest SABER semidiurnal tide is found in April, with a mean amplitude of $\sim 6 \mathrm{~K}$ and in October with a mean amplitude of $\sim 4.5 \mathrm{~K}$ at $100 \mathrm{~km}$ height, and (iii) the vertical wavelength found by the lidar is $\sim 50 \mathrm{~km}$ in most of the months with the exception of the summer months when it is longer; in June however the tidal phase was almost independent of height indicating that the semidiurnal tide is evanescent or with very large vertical wavelength. The SABER tidal wavelengths at $40^{\circ} \mathrm{N}$ however are different from the lidar ones; they indicate slight seasonal variability and on the average their magnitudes are clustered near $\sim 35 \mathrm{~km}$. This significant difference between the lidar semidiurnal tide observed over Fort Collins and the SABER tide at $40^{\circ} \mathrm{N}$ defines a different contribution of the Hough modes; while for the lidar semidiurnal tide the Hough modes with very long vertical wavelengths $(2,2)$ and $(2,3)$ are dominant in summer the SABER tide is composed by modes with significantly shorter wavelength as $(2,4)$ and $(2,5)$ modes.

The main results from the detailed documentation of the global spatial structure (altitude between 70 and $120 \mathrm{~km}$ and latitude between $50^{\circ} \mathrm{N}$ and $50^{\circ} \mathrm{S}$ ) and temporal variability of the migrating semidiurnal tide derived from the SABER/TIMED temperatures can be summarized as follows:

- The seasonal behavior of the vertically upward propagating semidiurnal tide in the middle latitudes $\left( \pm 40^{\circ}\right)$ is dominated by strong annual oscillation with a winter maximum in the upper mesosphere $(90 \mathrm{~km})$ of both hemispheres. The winter maximum in the SH (in May) is larger than that in the NH (January-February) reaching average amplitudes respectively $8 \mathrm{~K}$ and $7 \mathrm{~K}$. For altitudes between 70 and $90 \mathrm{~km}$ besides the winter maximum an autumn (September in the NH and March in the $\mathrm{SH})$ tidal amplification is evident as well. The September maximum detected at northern middle latitudes is well documented by radar studies (Manson et al., 1999,
2002; Riggin et al., 2003). Above $90 \mathrm{~km}$ the tide grows very rapidly with increasing the height and changes it seasonal behavior. At $110 \mathrm{~km}$ height the semidiurnal tide is stronger in summer than in the winter. In the lower thermosphere the NH summer maximum (June and August peaks) is much stronger than that in the SH (November and March peaks) having values respectively $\sim 23 \mathrm{~K}$ and $\sim 13-15 \mathrm{~K}$. The seasonal variability of the tidal phase in the middle latitudes indicated that while in the NH the semidiurnal phase appears earlier in winter than in summer the opposite tendency is observed in the SH. The vertical phase gradient at both hemispheres indicated slight seasonal changes, therefore a mean vertical wavelength of $\sim 35 \mathrm{~km}$ is observed during most of the year.

- The strongest migrating semidiurnal tide has been derived at tropical latitudes $\left( \pm 20-30^{\circ}\right)$. It indicated significant amplification between May and August in the lower thermosphere of both hemispheres. On the average, the semidiurnal temperature tide is stronger in the $\mathrm{SH}(32 \mathrm{~K})$ than that in the $\mathrm{NH}(30 \mathrm{~K})$ and the tidal amplitudes at $110 \mathrm{~km}$ height are nearly a factor of 5 larger than those at $90 \mathrm{~km}$. The migrating semidiurnal tide in both hemispheres revealed remarkable seasonal behavior at the altitude where it maximizes. In the $\mathrm{NH}$ at $110 \mathrm{~km}$ height the tidal amplitude indicated repeatable each year maxima exactly in May-June and AugustSeptember (upper left plot of Fig. 6). The same remarkable seasonal behavior has been found for the semidiurnal tide in the $\mathrm{SH}$ at $115 \mathrm{~km}$ height where the maxima are observed in May and August (upper right plot of Fig. 6). However, while the main maximum in the $\mathrm{NH}$ is that in August-September, in the SH is that in May. The seasonal variability of the tidal phase in the tropical latitudes indicated similar variability at both hemispheres: the phase appears earlier in summer than in winter. The vertical phase gradients are larger in winter than in summer and this determines the larger vertical wavelengths in summer $(\sim 38-50 \mathrm{~km})$ than in winter $(\sim 25-35 \mathrm{~km})$.

- The weakest semidiurnal tide in the lower thermosphere is observed over the equator. However, in the lower mesosphere $(\sim 70-80 \mathrm{~km})$ it usually has the largest amplitudes (see the bottom plot of Fig. 1) but its seasonal variability did not indicate a regular behavior. The equatorial semidiurnal tide amplifies significantly above $105 \mathrm{~km}$ height and its temporal variability is dominated by a main maximum in boreal summer months and a secondary one in winter months. The altitude phase structure (bottom plot of Fig. 8) revealed vertically upward propagating semidiurnal tide during the entire year only above $\sim 95-100 \mathrm{~km}$ height.

- The SABER migrating semidiurnal tide revealed quite complicated spatial features indicating that at different 
altitudes and seasons different tidal modes shape its latitude structure. The symmetric $(2,4)$ and antisymmetric $(2,5)$ modes seem to have a main effect in June (left plot of Fig. 10a), while in December (right plot of Fig. 10a) the contribution of the symmetric $(2,6)$ mode is evident as well. During equinoxes the migrating semidiurnal tide seems to consist mainly of symmetric $(2,4)$ and $(2,6)$ modes (Fig. 10b).

- The migrating semidiurnal tide at middle latitudes of the $\mathrm{NH}$ revealed some interannual variability observed in the lower thermosphere. At least part of it is connected with the effect of QBO and the mean (for the studied 6 years) amplitude of the QBO tidal modulation is $\sim 2-$ $2.5 \mathrm{~K}$. Similar effect has been found in the $\mathrm{SH}$ as well but the amplitude of QBO tidal modulation is two times smaller than that in the NH.

The presented detailed study of the climatological global tidal structure and temporal variability of the migrating semidiurnal temperature tide in the latitude range of $\pm 50^{\circ}$ and altitudes between $70 \mathrm{~km}$ and $120 \mathrm{~km}$ could provide important constraints for numerical models.

Acknowledgements. We are grateful to the SABER team for the access to the data on http://saber.gats-inc.com and to the NOAA Climate Prediction Center for the access to the QBO index on http://www.cpc.ncep.noaa.gov/. One of the authors, DP, is thankful to F. Huang, A. Smith and R. Lieberman for the useful discussions. We thank the anonymous reviewers for their insightful comments on the original manuscript.

Topical Editor C. Jacobi thanks two anonymous referees for their help in evaluating this paper.

\section{References}

Angelats i Coll, M. and Forbes, J. M.: Nonlinear interactions in the upper atmosphere: The $s=1$ and $s=3$ nonmigrating semidiurnal tides, J. Geophys. Res., 107, A8, doi:10.1029/2001JA900179, 2002.

Avery, S. K., Vincent, R. A., Phillips, A., Manson, A. H., and Fraser, G. J.: High-latitude tidal behavior in the mesosphere and lower thermosphere, J. Atmos. Terr. Phys., 51, 595-608, 1989.

Bernard R.: Variability of the semi-diurnal tide in the upper mesosphere, J. Atmos. Terr. Phys., 43, 663-674, 1981.

Burrage, M. D., Wu, D. L., Skinner, W. R., Ortland, D. A., and Hays, P. B.: Latitude and seasonal dependence of the semidiurnal tide observed by the high-resolution Doppler imager, J. Geophys. Res., 100(D6), 11313-11321, 1995.

Chapman, S. and Lindzen, R. S.: Atmospheric Tides: Thermal and Gravitational, 200 pp., Gordon and Breach, New York, 1970.

Clark, R. R. and Salah, J. E.: Propagation of the solar semidiurnal tide in the mesosphere and lower thermosphere at midlatitudes, J. Geophys. Res., 96, 1129-1133, 1991.

Forbes, J. M. and Garret, H. B.: Theoretical studies of atmospheric tides, Rev. Geophys., 17, 1951-1981, 1979.

Forbes, J. M.: Atmospheric tides, 2, The solar and lunar semidiurnal components, J. Geophys. Res., 87, 5241-5252, 1982.
Forbes, J. M. and Vial, F.: Monthly simulations of the solar semidiurnal tide in the mesosphere and lower thermosphere, J. Atmos. Terr. Phys., 51, 649-661, 1989.

Forbes, J. M.: Tidal and planetary waves, in: The Upper Mesosphere and Lower Thermosphere: A Review of Experiment and Theory, Geophys. Monogr. Ser., vol. 8, pp. 67-87, AGU, Washington, D.C., 1995.

Forbes, J. M., Hagan, M. E., Zhang, X., and Hamilton, K.: Upper atmosphere tidal oscillations due to latent heat release in the tropical troposphere, Ann. Geophys., 15, 1165-1175, 1997, http://www.ann-geophys.net/15/1165/1997/.

Forbes, J. M. and Wu, D.: Solar tides as revealed by measurements of mesosphere temperature by the MLS experiment on UARS, J. Atmos. Sci., 63, 1776-1797, 2006.

Forbes, J. M., Russell, J., Miyahara, S., Zhang, X., Palo, S., Mlynczak, M., Mertens, C. J., and Hagan, M. E.: Tropospherethermosphere tidal coupling as measure by the SABER instrument on TIMED during July-September 2002, J. Geophys. Res., 111, A10S06, doi:10.1029/2005JA011492, 2006.

Forbes, J. M., Zhang, X., Palo, S., Russell, J., Mertens, C. J., and Mlynczak, M.: Tidal variability in the ionospheric dynamo region, J. Geophys. Res., 113, A02310, doi:10.1029/2007JA012737, 2008.

Garcia, R. R., Marsh, D. R., Kinnison, D. E., Boville, B. A., and Sassi, F.: Simulations of secular trends in the middle atmosphere, 1950-2003, J. Geophys. Res., 112, D09301, doi:10.1029/2006JD007485, 2007.

Garcia-Comas, M., Lopez-Puertas, M., Marshall, B. T., et al.: Errors in Sounding of the Atmosphere using Broadband Emission Radiometry (SABER) kinetic temperature caused by nonlocal-thermodynamic-equilibrium model parameters, J. Geophys. Res., 113, D24106, doi:10.1029/2008JD010105, 2008.

Groves, G. V.: Hough components of water vapor heating, J. Atmos. Terr. Phys., 44, 281-290, 1982a.

Groves, G. V.: Hough components of ozone heating, J. Atmos. Terr. Phys., 44, 111-121, 1982 b.

Hagan, M., Vial, F., and Forbes, J.: Variability in the upper propagating semidiurnal tide due to effects of QBO in the lower atmosphere, J. Atmos. Terr. Phys., 54, 1465-1474, 1992.

Hagan, M., Forbes, J., and Vial, F.: On modeling migrating solar tides, Geophys. Res. Lett., 22, 893-896, 1995.

Hagan, M. E.: Comparative effects of migrating solar sources on tidal signatures in the middle and upper atmosphere, J. Geophys. Res., 101(D16), 21213-21222, 1996.

Hagan, M. E., Burrage, M. D., Forbes, J. M., Hackney, J., Randel, W. J., and Zhang, X.: GSWM-98: Results for migrating solar tides, J. Geophys. Res., 104(A4), 6813-6827, doi:10.1029/1998JA900125, 1999.

Hagan, M. E., Roble, R. G., and Hackney, J.: Modeling thermospheric tides, J. Geophys. Res., 106, 12739-12752, 2001.

Hagan, M. E. and Forbes, J. M.: Migrating and nonmigrating semidiurnal tides in the upper atmosphere excited by tropospheric latent heat brelease, J. Geophys. Res., 108(A2), 1062, doi:10.1029/2002JA009466, 2003.

Hamilton, K.: Latent heat release as a possible forcing mechanism for atmospheric tides, Mon. Weather Rev., 109, 3-17, 1981.

Huang, F. T., Mayr, H. G., Reber, C. A., Russell, J. M., Mlynczak, M., and Mengel, J. G.: Stratospheric and mesospheric temperature variations for the quasi-biennial and semiannual (QBO 
and SAO) oscillations based on measurements from SABER (TIMED) and MLS (UARS), Ann. Geophys., 24, 2131-2149, 2006, http://www.ann-geophys.net/24/2131/2006/.

Huang, F. T., Mayr, H. G., Reber, C. A., Russell, J. M., Mlynczak, M., and Mengel, J. G.: Ozone quasi-biennial oscillation (QBO), semiannual oscillations (SAO), and correlations with temperature in the mesosphere, lower thermosphere, and stratosphere, based on measurements from SABER on TIMED and MLS on UARS, J. Geophys. Res., 113, A01316, doi:10.1029/2007JA012634, 2008.

Jacobi, Ch., Portnyagin, Yu., Solovjova, T., Hoffmann, P., Singer, W., Fahrutdinova, A., Ishmuratov, R., Beard, G., Mitchell, N., Muller, G., Schminder, R., Kürschner D., Manson, A., and Meek, C.: Climatology of the semidiurnal tide at $52^{\circ} \mathrm{N}-56^{\circ} \mathrm{N}$ from ground-based radar wind measurements 1985-1995, J. Atmos. Sol.-Terr. Phys., 61, 975-991, 1999.

Kong, A. K. H., Charles, P. A., and Kuulkers, E.: Long-term X-ray variability in GX 354-0, New Astronomy, 3(5), 301-307, 1998.

Manson, A. H., Meek, C. E., Schminder, R., Kürschner, D., Clark, R. R., Müller, H. G., Vincent, R. A., Phillips, A., Fraser, G. J., Singer, W., and Kazimirovsky, E. S.: Tidal winds from the MLT global radar network during the first LTCS campaign September 1987, J. Atmos. Terr. Phys. 52, 175-183, 1990.

Manson, A. H., Meek, C. E., Hagan, M., Hall, C., Hocking, W., MacDougall, J., Franke, S., Riggin, D., Fritts, D., Vincent, R., and Burrage, M.: Seasonal variations of the semi-diurnal tides in the MLT: multi-year MF radar observations from 2 to $70^{\circ} \mathrm{N}$, and the GSWM tidal model, J. Atmos. Sol.-Terr. Phys. 61, 809-828, 1999.

Manson, A. H., Meek, C., Hagan, M., Koshyk, J., Franke, S., Fritts, D., Hall, C., Hocking, W., Igarashi, K., MacDougall, J., Riggin, D., and Vincent, R.: Seasonal variations of the semi-diurnal and diurnal tides in the MLT: multi-year MF radar observations from $2-70^{\circ} \mathrm{N}$, modelled tides (GSWM, CMAM), Ann. Geophys., 20, 661-677, 2002, http://www.ann-geophys.net/20/661/2002/.

Manson, A. H., Meek, C. E., Hall, C.M., Nozawa, S., Mitchell, N.J., Pancheva, D., Singer, W., and Hoffmann, P.: Mesopause dynamics from the scandinavian triangle ofradars within the PSMOSDATAR Project, Ann. Geophys., 22, 367-386, 2004,

http://www.ann-geophys.net/22/367/2004/.

McLandress, C., Rochon, C. Y., Shepherd, G. G., Solheim, B. H., Thuillier, G., and Vial, F.: The meridional wind component of the thermospheric tides observed by WINDII on UARS, Geophys. Res. Lett., 21, 2417-2420, 1994.

McLandress, C., Shepherd, G. G., and Solheim, B. H.: Satellite observations of thermospheric tides: Results from the Wind Imaging Interferometer on UARS, J. Geophys. Res., 101(D2), 40934114, doi:10.1029/95JD03359, 1996.

Mertens, C. J., Mlynczak, M., Lopez-Puertas, M., et al.: Retrieval of mesospheric and lower thermospheric kinetic temperature from measurements of $\mathrm{CO}_{2} 15 \mu \mathrm{m}$ earth limb emission under nonLTE conditions, Geophys. Res. Lett., 28, 1391-1394, 2001.

Mertens, C. J., Schmidlin, F. J., Goldberg, R. A., et al.: SABER observations of mesospheric temperature and comparisons with falling sphere measurements taken during the 2002 summer MaCWINE campaign, Geophys. Res. Lett., 31, J03105, doi:10.1029/2003GL018605, 2004.

Mitchell, N. J., Pancheva, D., Middleton, H., and Hagan, M.: Mean winds and tides in the Arctic mesosphere/lower thermosphere re- gion and comparison with the GSWM, J. Geophys. Res., 106, A1, doi:10.1029/2001JA900127, 2002.

Mukhtarov, P., Pancheva, D., and Andonov, B.: Global structure and seasonal and interannual variability of the migrating diurnal tide seen in the SABER/TIMED temperatures between 20 and 120 km, J. Geophys. Res., 114, in press, 2009.

Pancheva, D., Mukhtarov, P., Mitchell, N. J., Beard, A. G., and Muller, H. G.: A comparative study of winds and tidal variability in the mesosphere/lower-thermosphere region over Bulgaria and the UK, Ann. Geophys., 18, 1304-1315, 2000,

http://www.ann-geophys.net/18/1304/2000/.

Pancheva, D., Mitchell, N. J., Hagan, M. E., et al.: Global-scale tidal structure in the mesosphere \& lower thermosphere during the PSMOS campaign summer-99 and comparison with the Global Scale Wave Model, J. Atmos. Sol.-Terr. Phys., 64, 10111035, 2002.

Pancheva, D. V. and Mitchell, N. J.: Planetary waves and variability of the semidiurnal tide in the mesosphere and lower thermosphere over Esrange $\left(68^{\circ} \mathrm{N}, 21^{\circ} \mathrm{E}\right)$ during winter, J. Geophys. Res., 109, A08307, doi:10.1029/2004JA010433, 2004.

Pancheva, D., Mukhtarov, P., Mitchell, N. J., Merzlyakov, E., Smith, A.K., Andonov, B., Singer, W., Hocking, W., Meek, C., Manson, A., and Murayama, Y.: Planetary waves in coupling the stratosphere and mesosphere during the major stratospheric warming in 2003/2004, J. Geophys. Res., 113, D12105, doi:10.1029/2007JD009011, 2008.

Pancheva, D., Mukhtarov, P., Andonov, B., Mitchell, N. J., and Forbes, J. M.: Planetary waves observed by TIMED/SABER in coupling the stratosphere-mesosphere-lower thermosphere during the winter of 2003/2004: Part 1, Comparison with the UKMO temperature results, J. Atmos. Sol.-Terr. Phys., 71, 61-74, 2009a.

Pancheva, D., Mukhtarov, P., Andonov, B., Mitchell, N. J., and Forbes, J. M.: Planetary waves observed by TIMED/SABER in coupling the stratosphere-mesosphere-lower thermosphere during the winter of 2003/2004: Part 2, Altitude and latitude planetary wave structure, J. Atmos. Sol.-Terr. Phys., 71, 75-87, 2009 b.

Portnyagin Yu. I. and Kajdalov, O. V.: Tides in the $80-100 \mathrm{~km}$ height region, J. Atmos. Terr. Phys., 48, 1159-1173, 1986.

Riggin, D. M., Meyer, C. K., Fritts, D. C., Jarvis, M. J., Murayama, Y., Singer, W., Vincent, R. A., and Murphy, D. J.: MF radar observations of seasonal variability of semidiurnal motions in the mesosphere at high northern and southern latitudes, J. Atmos. Sol.-Terr. Phys., 65, 483-493, 2003.

Russell III, J. M., Mlynczak, M. G., Gordley, L. L, Tansock, J., and Esplin, R.: An overview of the SABER experiment and preliminary calibration results, Proceedings of the SPIE, 44th Annual Meeting, Denver, Colorado, 18-23 July, vol. 3756, $277-$ 288. 1999.

She, C. Y., Li, T., Collins, R. L., et al.: Tidal perturbations and variability in the mesopause region over Fort Collins, CO $(41 \mathrm{~N}, 105 \mathrm{~W})$ : Continuous multi-day temperature and wind lidar observations, Geophys, Res. Lett., 31, L2411, doi:10.1029/2004GL021165, 2004.

Vial, F.: Numerical simulations of atmospheric tides for solstice conditions. J. Geophys. Res., 91, 8955-8969, 1986.

Vial, F.: Causes of tidal variability, NATO ASI Series "Coupling Processes in the Lower and Middle Atmosphere", edited by: Thrane, E., Blix, T., Fritts, D., Kluwer Academic, 1989.

Vincent, R., Kovalam, A. S., Fritts, D. D., and Isler, J. R.: 
Long-term MF radar observations of solar tides in the lowlatitude mesosphere: Interannual variability and comparison with the GSWM, J. Geophys. Res., 103(D8), 8667-8684, doi:10.1029/98JD00482, 1998.

Williams, C. R. and Avery, S. K.: Diurnal nonmigrating tidal oscillations forced by deep convective clouds, J. Geophys. Res., 101, 4079-4091, 1996.

Zhang, X., Forbes, J. M., Hagan, M. E., Russell III, J. M., Palo, S. E., Mertens, C. J., and Mlynczak, M. G.: Monthly tidal temperatures 20-120 km from TIMED/SABER, J. Geophys. Res., 111, A10S08, doi:10.1029/2005JA011504, 2006.
Yuan, T., Schmidt, H., She, C. Y., Krueger, D. A., and Reising, S.: Seasonal variations of semidiurnal tidal perturbations in mesopause region temperature and zonal and meridional winds above Fort Collins, Colorado $\left(41^{\circ} \mathrm{N}, 105^{\circ} \mathrm{W}\right)$, J. Geophys. Res., 113, D20103, doi:10.1029/2007JD009687, 2008. 